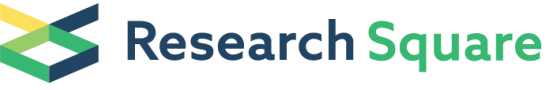 \\ Preprints are preliminary reports that have not undergone peer review. They should not be considered conclusive, used to inform clinical practice, or referenced by the media as validated information.
}

\section{Nuclear Magnetic Resonance-based Metabolomics of Blood Plasma from Dairy Calves Infected with the Main Causal Agents of Bovine Respiratory Disease (BRD)}

\section{Mariana Santos-Rivera}

Department of Biochemistry, Molecular Biology, Entomology, and Plant Pathology, Mississippi State University, Mississippi State, MS, USA 39762

\section{Nicholas C. Fitzkee}

Department of Chemistry, Mississippi State University, Mississippi State, MS, USA 39762

Rebecca A. Hill

Department of Chemistry, Mississippi State University, Mississippi State, MS, USA 39762

\section{Richard E. Baird}

Department of Biochemistry, Molecular Biology, Entomology, and Plant Pathology, Mississippi State University, Mississippi State, MS, USA 39762

\section{Ellianna Blair}

Department of Biochemistry, Molecular Biology, Entomology, and Plant Pathology, Mississippi State University, Mississippi State, MS, USA 39762

\section{Merrilee Thoresen}

College of Veterinary Medicine, Pathobiology \& Population Medicine, Mississippi State University, Mississippi State, MS, USA 39762

\section{Amelia R. Woolums}

College of Veterinary Medicine, Pathobiology \& Population Medicine, Mississippi State University, Mississippi State, MS, USA 39762

\section{Florencia Meyer}

Department of Biochemistry, Molecular Biology, Entomology, and Plant Pathology, Mississippi State University, Mississippi State, MS, USA 39762

\section{Carrie K. Vance ( $\nabla$ ckv7@msstate.edu )}

Department of Biochemistry, Molecular Biology, Entomology, and Plant Pathology, Mississippi State University, Mississippi State, MS, USA 39762

\section{Research Article}

Keywords: $1 \mathrm{H}$ - NMR, biomarkers, bovine respiratory syncytial virus (BRSV), challenge study, chemometrics, Mannheimia haemolytica $(\mathrm{MH})$, multivariate analysis 
Posted Date: October 20th, 2021

DOl: https://doi.org/10.21203/rs.3.rs-960865/v1

License: (c) (i) This work is licensed under a Creative Commons Attribution 4.0 International License. Read Full License 


\section{Abstract}

Each year, Bovine Respiratory Disease (BRD) results in significant economic loss in the cattle sector, and novel metabolic profiling and early diagnosis techniques represent a promising tool for developing effective measures for disease management. Here, proton - Nuclear Magnetic Resonance ( ${ }^{1} \mathrm{H}$ - NMR) spectra were used to characterize metabolites from blood plasma collected from dairy calves intentionally infected with the main BRD causal agents, bovine respiratory syncytial virus (BRSV) and Mannheimia haemolytica $(\mathrm{MH})$, to generate a well-defined metabolomic profile under controlled conditions. In response to infection, 42 metabolites (BRSV = 27, $\mathrm{MH}=24$ ) changed in concentration compared to the Baseline (non-infected) state. Fuel substrates and products exhibited a particularly strong effect, reflecting imbalances that occur during the immune response. Glucose levels decreased only during bacterial infection, suggesting that the clinical signs of bacterial BRD are more energetically taxing than those of viral BRD. Furthermore, ${ }^{1} \mathrm{H}$ - NMR spectra from Baseline and Infected samples were discriminated with an accuracy, sensitivity, and specificity $\geq 95 \%$ using chemometrics to model the changes associated with disease, suggesting that metabolic profiles can be used for further development and validation of diagnostic tools.

\section{Introduction}

One of the most severe and costly health problems worldwide is bovine respiratory disease (BRD), a disease complex caused by numerous microbial pathogens ${ }^{1-4}$. Prevalent causal agents for BRD include viral (bovine herpes-virus type 1, bovine respiratory syncytial virus, bovine viral diarrhea virus, parainfluenza-3 virus, and bovine coronavirus), and bacterial (Mannheimia haemolytica, Pasteurella multocida, Haemophilus somnus, Mycoplasma bovis) pathogens ${ }^{1,5}$. Bovine respiratory syncytial virus (BRSV) is a major cause of respiratory disease in young calves ( $\leq 1$ year). This viral infection can be asymptomatic and can involve the upper and lower respiratory tracts ${ }^{6,7}$. BRSV typically initiates infection in response to physiological and environmental stressors, suppressing the host's defense mechanisms and predisposing the replication, inhalation, and colonization of the lungs by M. haemolytica, a microorganism found in the normal flora of the upper respiratory system in ruminants ${ }^{1,8,9}$.

In general, viral and bacterial agents activate innate immunity, which is comprised of nonspecific defense mechanisms that are triggered shortly after the appearance of the antigen ${ }^{10}$. This occurs as a result of the production of a motif of molecules expressed by the pathogen known as pathogen - associated molecular patterns (PAMPs) ${ }^{11,12}$. In the case of BRSV the PAMPs are known components consisting of glycoprotein $\mathrm{G}$, fusion protein $\mathrm{F}$, and single - stranded RNA ${ }^{6}$. For M. haemolytica, PAMPs include flagellin, lipopolysaccharide (LPS) complex, and leukotoxin (LKT) ${ }^{13}$. These elicitors are identified by pattern recognition receptors (PRRs) for rapid detection of the threat from a potential pathogen ${ }^{11}$. Surface-bound and intracellular PRRs, such as Toll-like receptors (TLRs), nucleotide-binding and oligomerization domain (NOD) - like receptors, and RNA helicases, are expressed by bovine respiratory tract cells ${ }^{12}$. The engagement of PAMPs by PRRs results in the production of damage-associated molecular patterns 
(DAMPs), initiating ATP - dependent signaling cascades. Activated transcription factors induce the production of inflammatory cytokines and chemokines for release into the body, which attracts neutrophils, macrophages, and lymphocytes to the respiratory tract, resulting in respiratory disease $e^{6,9,11}$.

The standard in - field method for BRD detection is the visual - clinical diagnosis (VCD) of cattle appearance and behavior following clinical signs such as high temperature, respiratory discomfort, and other factors considered problematic when determining the condition of infected calves ${ }^{14}$. This diagnostic methodology has less than $65 \%$ sensitivity, meaning that around $35 \%$ of infections are not detected, and $65 \%$ specificity, such that $35 \%$ of healthy cattle are unnecessarily treated ${ }^{15,16}$. Thus, alternative methods to VCD are needed to profile the infection and definitively detect BRD before its manifestation, which will enable farmers to respond with the proper prophylactic measures ${ }^{17}$. A comprehensive phenotypic assessment for BRD using a specific "omics" platform could be obtained from blood plasma or other biofluids. To this end, metabolomics profiling of disease state using nuclear magnetic resonance (NMR) is a means to validate both the traditional diagnostic approach (i.e., VCD) and the biochemical processes occurring throughout infection, which may be detectable using more timely and efficient diagnostic techniques such as Near Infrared Spectroscopy (NIRS) ${ }^{17-19}$.

NMR - based metabolomics provides a window into metabolic mechanisms by combining high throughput analytical chemistry with multivariate data analysis $(M V A)^{20}$ to identify and quantify changes in metabolic products of a biological system ${ }^{21,22}$. Proton NMR $\left({ }^{1} \mathrm{H}\right.$ - NMR) spectra arise from active nuclei absorbing electromagnetic energy at the frequencies specific to the ${ }^{1} \mathrm{H}$ nucleus, resulting in resonance within a two - level quantum system ${ }^{23}$. This resonance frequency, along with the signal intensity, is specific to the local covalent - bonding structure and chemical environment and is reflected in the manifold of information - rich signals (chemical shifts) in NMR spectra ${ }^{23,24}$. Blood plasma is the most frequently used biofluid for NMR studies ${ }^{17,18,25}$, and consists of the protein - rich fraction of blood in which white blood cells (WBC), red blood cells $(R B C)$, platelets $(P T L)$, and coagulation factors are suspended before blood fractionation with an anticoagulant ${ }^{26}$. Bovine blood plasma is composed of water (92\%); albumin and globulins (3\%) required to maintain colloidal osmotic pressure; immunoglobulins (4\%) used for signal transduction and response to antigens; coagulants and fibrinogen $(0.4 \%)$ that aid in blood clotting; minerals $(0.5 \%)$ required to maintain blood $\mathrm{pH}$, and lipids $(0.07 \%)$ associated with hormone content and nutrition. Blood plasma is commonly used to diagnose viral or bacterial infections by detecting antigens or pathogen-specific antibodies using ELISA (Enzyme-Linked Immuno-Sorbent Assay) ${ }^{26}$. Recently, blood plasma was shown to be a suitable medium for detecting $M$. haemolytica infection using NIRS ${ }^{19}$.

In cattle, NMR has been used to conduct metabolic profiling and diagnosis of both reproductive and nutritional disorders ${ }^{27-32}$. In one case, seven plasma metabolites (alanine, arginine, choline, isoleucine, leucine, phosphatidyl choline, and valine) were shown to significantly decrease in dairy cows during estrous compared to cows in anestrous. These changes were related to glucose, triglyceride, and amino acid metabolic pathways associated with postpartum anestrus ${ }^{27}$. Similarly, changes in the concentration 
of metabolites in blood plasma were observed in Holstein cows during postpartum and lactation periods, revealing that glucose is rerouted to synthesize lactose and fats in milk, causing the lactating cow to produce ketone bodies as an alternative energy source to maintain homeostasis ${ }^{28-31}$. Metabolic profiles related to fatty liver disease in lactating cows were correlated with increases in $\beta$-hydroxybutyric acid, acetone, citrulline, glycine, isobutyrate, trimethylamine-N-oxide, and valine, and decreases in $\gamma^{-}$ aminobutyric acid glycerol, alanine, asparagine, creatinine, and glucose, suggesting this metabolic disorder alters the concentration of metabolites related to energy imbalance pathways ${ }^{32}$. In contrast, NMR analysis revealed calves with bronchopneumonia detected by VCD exhibited increases in 2-methyl glutarate, phenylalanine, phosphatidylcholine, but decreases in acetate, allantoin, cholesterol, dimethyl sulfone, ethanol, propionate, and free cholesterol in the blood plasma, suggesting alteration of a different set of metabolic pathways ${ }^{33}$. Recently, feedlot cattle that were deemed to have BRD through VCD inspection were shown to have significant alterations in the concentration of a-glucose chains, hydroxybutyrate, and phenylalanine by NMR analysis of blood plasma ${ }^{34}$. Results from both of these studies $^{33,34}$, combined with recent work in which NIRS profiling of blood plasma of calves with induced M. haemolytica infection ${ }^{19}$, indicate that characteristic shifts in the metabolome of blood plasma may be indicative of BRD infection and perhaps pathogenic specificity.

Here, we conduct bovine infection trials, known as challenge studies, in which dairy calves were intentionally infected with the main BRD causal agents, BRSV and M. haemolytica $(\mathrm{MH})$, in order to generate a well - defined metabolomic profile under controlled conditions. ${ }^{1} \mathrm{H}$ - NMR analysis of the collected blood plasma was used to (1) identify metabolites associated with infection by the two different pathogens, (2) assess concentration changes of those metabolites between the healthy and infected stages and in response to each pathogen, (3) generate a model for discriminating ${ }^{1} \mathrm{H}$ - NMR spectra, and the metabolites involved in the differentiation of healthy and infected calves for each causal agent, and (4) provide new biochemical information to the current blood plasma NMR - BRD metabolome, which was acquired in non-controlled field conditions ${ }^{33,34}$, in order to provide insight into quantifiable differences between causal agents that might be targeted for the development and validation of novel BRD management strategies.

\section{Materials And Methods}

\section{Animals and controlled challenges.}

Ten non - immunized Holstein steers were subjected to two controlled challenge studies, each with a different infectious agent. The first group of dairy calves $(n=5)$ was challenged with M. haemolytica (isolate D153) via bronchoalveolar lavage catheterization during the summer of 2019. The second group $(n=5)$ was challenged with BRSV (GA - 1, P5) delivered by a nebulizer (DeVilbiss Pulmo - Neb) through a custom - made face mask during the fall of the same year. The detailed procedures of pathogen preparation and challenge administration are described in the supplementary information (Supplementary Methods S1 online). The calves were sheltered at Mississippi State University (MSU), and 
the experiments were carried out with the approval of the MSU-Institutional Animal Care and Use Committee. All methods were performed following MSU-IACUC guidelines and regulations (IACUC-19037) and reported in compliance with the ARRIVE (Animal Research: Reporting In Vivo Experiments) guidelines 2.0. VCD and complete blood counts (CBC) were measured following published procedures for 27 days during the bacterial challenge and for 34 days during the viral challenge ${ }^{19,34}$. For the BRSV challenge study, three more days were assessed prior to inducing infection while awaiting serological results to confirm the absence of antibodies against this pathogen. In general, blood samples and VCD data were collected prior to induced infection for four days, after the infection for 11 continuous days, and then every other day from days 12 - 23 post - challenge.

\section{Blood acquisition.}

Blood samples ( $n=202)$ were drawn via jugular venipuncture and immediately placed on ice in two collection tubes containing the anticoagulant EDTA (ethylenediaminetetraacetic acid). The first tube was centrifuged at $4000 \mathrm{rpm}$ for 20 minutes to separate plasma, and duplicates of $1 \mathrm{~mL}$ were stored at $-80^{\circ} \mathrm{C}$ until NMR analysis. The second tube was used for $\mathrm{CBC}$, where RBC, hematocrit (HTC), hemoglobin (HGB), WBC, and PTL contents were acquired using a veterinary hematology analyzer. In addition, microscopic differential counts of WBC were performed to assess the variability of neutrophils, eosinophils, basophils, monocytes, and lymphocytes. The viral and bacterial challenge studies yielded a total of 97 and 105 blood samples, respectively. Based on VCD as the reference method, blood samples were classified as Baseline, Asymptomatic, Infected, Treated, or Recovered. To avoid interference of antibiotics or the recovery processes in the interpretation of the NMR metabolomic profiles, only data from the samples designated as Baseline $(n=55)$ and Infected $(n=47)$ were used in the univariate and multivariate analyses (Table 1). 
Table 1

Dairy calves and the number of blood samples selected for NMR metabolomic profiling. An even number of samples per category (Baseline or Infected) were chosen to ensure variance and weight homogeneity of each data set for the multivariate analyses.

\begin{tabular}{|c|c|c|c|c|c|c|}
\hline Challenge & $\begin{array}{l}\text { Calf } \\
\text { ID }\end{array}$ & $\begin{array}{l}\text { Age } \\
\text { (months) }\end{array}$ & $\begin{array}{l}\text { Weight } \\
\text { (kg) }\end{array}$ & $\begin{array}{l}\text { Baseline } \\
\text { samples }\end{array}$ & $\begin{array}{l}\text { Infected } \\
\text { samples }\end{array}$ & Total \\
\hline \multirow[t]{5}{*}{ BRSV } & 1 & 3.2 & 135 & $4 / 7$ & $4 / 4$ & $8 / 11$ \\
\hline & 2 & 3.2 & 135 & $4 / 7$ & $4 / 4$ & $8 / 11$ \\
\hline & 3 & 3.0 & 130 & $4 / 7$ & $4 / 4$ & $8 / 11$ \\
\hline & 4 & 2.9 & 125 & $4 / 7$ & $4 / 4$ & $8 / 11$ \\
\hline & 5 & 2.4 & 125 & $4 / 7$ & $4 / 5$ & $8 / 12$ \\
\hline \multirow{5}{*}{$\begin{array}{l}\text { M. } \\
\text { haemolytica }\end{array}$} & 6 & 6 & 204 & $3 / 4$ & $3 / 3$ & $6 / 7$ \\
\hline & 7 & 6 & 196 & $3 / 4$ & $3 / 14$ & $6 / 18$ \\
\hline & 8 & 6 & 145 & $3 / 4$ & $3 / 3$ & $6 / 7$ \\
\hline & 9 & 5 & 124 & $3 / 4$ & $3 / 3$ & $6 / 7$ \\
\hline & 10 & 5 & 142 & $3 / 4$ & $3 / 3$ & $6 / 7$ \\
\hline Total samples & & & & $35 / 55$ & $35 / 47$ & $70 / 102$ \\
\hline
\end{tabular}

\section{Preparation of blood plasma for ${ }^{1} \mathrm{H}$ - NMR analysis.}

Before collecting NMR spectra, proteins and larger macromolecules were removed from the samples using filters with a $3 \mathrm{~K}$ molecular weight cutoff (Microsep, Pall Corporation, Ann Arbor, MI). Following filtration, $330 \mu \mathrm{L}$ of each filtered plasma sample was added to $330 \mu \mathrm{L}$ of sterile referencing solution ${ }^{35}$, which consisted of $200 \mathrm{mM}$ sodium phosphate buffer, $1 \mathrm{mM} 3$ - trimethylsilylpropionate 2, 2, 3, 3 - d4 (TMSP - d4, Cambridge Isotope Labs DLM - 48 - 5) and $0.1 \%(\mathrm{w} / \mathrm{v})$ sodium azide $\left(\mathrm{NaN}_{3}\right)$ in $50 \%$ deuterium oxide $\left(D_{2} \mathrm{O}\right.$, Cambridge Isotope Labs DLM - 4 - 99). Then, $600 \mu \mathrm{L}$ of the mixture was transferred to a clean NMR tube (Wilmad LabGlass, 535 - PP - 7) and kept at $4^{\circ} \mathrm{C}$ for less than $24 \mathrm{~h}$ before NMR data acquisition.

\section{${ }^{1} \mathrm{H}$ - NMR spectra collection.}

For each pathogen challenge, an even number of Baseline and Infected blood plasma samples $(n=70)$ were chosen for NMR analysis to ensure homogeneity of the variance and weight of each data set for the statistical analyses (Table 1); the detailed information from these samples can be found in the supplementary material (Supplementary Table S1 online). A Bruker Avance III HD $500 \mathrm{MHz}$ spectrometer outfitted with a 5 - mm BBFO probe (Bruker, Massachusetts, USA) was used for NMR spectroscopy. 
Samples were run in automation mode with a SampleJet, with all samples refrigerated at $4^{\circ} \mathrm{C}$ until just prior to loading. A perfect - echo WATERGATE sequence (PE - WATERGATE, parameter set ZGESGPPE) was applied to collect the data ${ }^{36}$. Data were collected at $298 \mathrm{~K}$ for 128 scans with a $1 \mathrm{~s}$ inter - scan delay and a $3 \mathrm{~s}$ per - scan acquisition time. The total acquisition time for each sample, including 3D - shimming, was about 15 minutes. Topspin 4.0.8 (Bruker, Massachusetts, USA) was used for spectral processing following the acquisition. All spectra were zero - filled to $128 \mathrm{k}$ points, and a $1 \mathrm{~Hz}$ line broadening was used. Automatic phasing and baseline correction were performed, ${ }^{1} \mathrm{H}$ - NMR spectra were segmented into successive non - overlapping regions of 0.0001 - ppm chemical shifts between 0.0 and $10.5 \mathrm{ppm}$, and the water region was truncated between 4.30 to $5.10 \mathrm{ppm}$. The processed spectra were then imported into the Chenomx NMR Suite 8.6 (Chenomx, Edmonton, Canada) to identify individual metabolites using a reference library containing 338 metabolites for $500 \mathrm{MHz}$ spectrometers. Because the Chenomx library was acquired using a NOESY - based 1D pulse sequence, the reported metabolite concentrations (mM) are likely to differ slightly from the actual concentrations. However, relative differences between samples will be preserved, and absolute concentration differences for the majority of compounds are expected ${ }^{37}$.

\section{Statistics.}

The mean and standard deviation (SD) for VCD and CBC parameters collected from the Infected stage of the BRSV challenge $(n=21)$, the M. haemolytica study $(n=26)$, and the combined Baseline data points from both challenge studies $(n=55)$ were calculated using univariate statistics. The same parameters were calculated for the concentration ( $\mathrm{mM}$ ) of metabolites chosen by comparing those found in this investigation to those previously reported for blood plasma in bovines and other mammals ${ }^{17,25,38}$. Metabolites related to the referencing solution, diet ingredients, or only detected in less than two samples per disease stage (Baseline or Infected) were excluded from the analyses. ANOVA and pairwise mean comparison (Baseline vs. BRSV, Baseline vs. MH, BRSV vs. MH) using Tukey - Kramer HSD (honestly significant difference) test with alpha $=0.05$ were used to assess for significance in parameter response for VCD, CBC, and metabolite concentration between the Baseline and Infected categories from both challenges. The results for these post - hoc tests were reported with connecting letters, with different letters indicating significant differences between the Baseline, BRSV, and MH categories (JMP® 14.0 SAS Institute Inc., NC. USA). In addition, a database of metabolite concentrations representing a general state of infection was composed of data collected from all Infection samples, regardless of pathogenic agent $(n=47)$, and was evaluated by a pairwise mean comparison (Baseline vs. Infected) using Student's $t$ test with alpha $=0.05$.

\section{Multivariate Analysis (MVA).}

The VCD and CBC parameters, and the metabolite concentrations, were subjected to Principal Component Analysis (PCA) using full cross-validation and algorithm - SVD (Singular Value Decomposition) to obtain correlation loadings plots to determine the magnitude and direction of a particular constituent's 
contribution (Influence) to the models created for the Baseline and Infected stages (Unscrambler® v. 11, Aspen Technology Inc., Massachusetts, USA). The processed ${ }^{1} \mathrm{H}$ - NMR spectra contained spectral peaks ranging from 0.5 to $9.0 \mathrm{ppm}$ that were chosen for the chemometrics - based MVA; peaks from free EDTA at $3.2 \mathrm{ppm}$ and $\mathrm{Ca}^{2+}$ - EDTA at $3.6 \mathrm{ppm}$ were removed prior to analysis ${ }^{39,40}$. Three balanced datasets of spectra were created: the first named Infected $(n=70)$ was created by combining information from both studies; the second corresponded to the BRSV challenge $(n=40)$, and the third to the M. haemolytica challenge $(n=30)$. SIMCA software - omics skin v.15.0 (Umetrics AB, Ume, Sweden) was used to apply pattern recognition methods. ${ }^{1} \mathrm{H}$ - NMR spectra were subjected to PCA, in which the scale data conversion with mean-center scaling reflects the total metabolic differences between the two groups (Baseline and Infected) as well as the degree of variability within each group ${ }^{41}$.

The ${ }^{1} \mathrm{H}$ - NMR spectra of blood plasma were analyzed using orthogonal partial least-squares discriminant analysis (OPLS - DA). The OPLS - DA models were built with $t[1] \mathrm{P}$ and $\mathrm{t}[2] 0$, which stand for the first principal component and the second orthogonal component, respectively ${ }^{41}$. The OPLS - DA models were used to maximize the covariance between the measured data $\left(X\right.$ variable, peak intensities in ${ }^{1} \mathrm{H}$ - NMR spectra) and the response variable ( $Y$ variable, predictive classifications). The quality of each model was assessed using $R^{2} X, R^{2}, R^{2} Y$, and $Q^{2}$, where $R^{2} X$ denotes the degree of optimization of the analytical model, $R^{2}$ symbolizes the coefficient of determination, $R^{2} Y$ denotes the percentage of variance explained by the model, and $\mathrm{Q}^{2}$ describes the model's cumulative prediction ${ }^{41,42}$. In the OPLS - DA models, a 7 segment cross - validation was used to estimate the optimal component number of each model to avoid over - fitting. In addition, the percentage of accuracy, sensitivity, and specificity were calculated to test the ability of each model to identify true positive and true negative samples correctly ${ }^{43}$. Permutation analysis $(n=200)$ was used to validate the OPLS - DA models and to assess model reliability. In permutation analysis a model is considered reliable if $R^{2}>0.4$ and the intercept $Q^{2}<041,42,44$.

\section{Results}

\section{Clinical and hematological results.}

Overall, all the calves showed similar patterns of health and disease during the controlled studies (Fig. 1). The typical activation of the innate immunity or nonspecific defense mechanisms following the bacterial challenge were observed after 24 hours of infection; the increase in rectal temperature (Fever) and WBC (Fig. 1a,b) is likely due to the release and recognition of the LPS complex and other pyrogenic features of M. haemolytica in the respiratory tract cells ${ }^{45}$. On Day 3 , after inducing infection, severe signs of disease were detected in four dairy calves (ID 6, 8, 9, and 10) which were then treated over five days with a broadspectrum antibiotic (Ceftiofur). The treatment caused the recovery of the calves and the change in the patterns for rectal temperature (TEMP) and WBC (Fig. 1a,b). Mild signs of infection from Day 1 until Day 19 were observed in calf 7; after D19, his signs intensified, and antibiotics were given. By contrast, dairy calves challenged with BRSV exhibited increased TEMP and WBC on Day 7 post-infection (Fig. 1a,b), 
which corresponds to the end of the asymptomatic phase, characteristic of the incubation period of this virus $^{6}$. In this challenge study, calf 2 died on Day 8 due to disease complications.

The results of the univariate and multivariate tests for the VCD and $C B C$ values for both challenges are shown in Fig. 2. In terms of the univariate analysis during the BRSV challenge, nine parameters (TEMP, RR, RBC, HCT, WBC, neutrophils, lymphocytes, eosinophils, and basophils) were statistically different ( $p<$ 0.05 ) during Infection compared to the Baseline, reflective of the innate immune response to virus replication in the respiratory cells ${ }^{6}$. Throughout the M. haemolytica infection, four of the evaluated variables (TEMP, RR, HCT, and PTL) were statistically different $(p<0.05)$ from the Baseline. These findings can be associated with the hemorrhage and edema known to be caused by the LPS complex produced by this bacterium ${ }^{46}$.

The PCA correlation loading plots for VCD and CBC (Fig. 3) show the relationships between the potential explanatory variables ( $\mathrm{X}$ - matrix) within each of the databases (Baseline, Infected, $\mathrm{BRSV}$, and $\mathrm{MH}$ ) for the development of models ${ }^{47}$. The inner ellipse represents $50 \%$, while the outer ellipse represents $100 \%$ of the explained variance for the individual variables. Thus, the area between the two ellipses explains 50 to $100 \%$ of the variance, implying that the centralized parameters (inside the inner circle) have an unimportant effect on the differentiation of each X - matrix. In contrast, those inside the outer circle (shaded) present a strong influence or significant impact on the differentiation of each model ${ }^{47,48}$. In addition, when the variables are placed in the positive or negative direction of the first principal component (PC - 1), this influence can be described as positively or negatively correlated within each Xmatrix, meaning the variables in those directions increase or decrease together to generate each model's characteristic patterns ${ }^{47,48}$.

The distribution of VCD and CBC variables for the Baseline model can be seen in Fig. 3a; this pattern was compared with those obtained in the Infected stage of each challenge separated and together. When evaluating the general infection database (Fig. 3b), a similar pattern was observed in comparison to the Baseline, with HGB negatively correlated, differing from the non-infected stage when it was found to have no influence in the model. For the BRSV infection model (Fig. 3c), TEMP, HGB, and HCT were positively correlated in comparison to the Baseline. The model for the evaluated variables during the $M$.

haemolytica infection (Fig. 3d) differed from the Baseline in which TEMP, RBC, HGB, HCT, and PLT were positively correlated.

\section{Metabolites detected by ${ }^{1} \mathrm{H}-\mathrm{NMR}$.}

The representative $500 \mathrm{MHz}{ }^{1} \mathrm{H}$ - NMR spectra of blood plasma collected with EDTA from dairy calves before and after the controlled infections are shown in Fig. 4. A total of 179 metabolites were identified using the batch profiler option in the Chenomx library. From these, a total of 72 metabolites were selected for the statistical analyses following the criteria explained in the methodology. After the selection, the presence of these metabolites was reliably identified in the samples manually using Chenomx. These 
compounds reproducibly appeared as well - resolved signals in the ${ }^{1} \mathrm{H}$ - NMR spectra, and overlapped signals were confirmed using at least two peak groups before fitting in the Chenomx profiler. After the manual confirmation of these metabolites, on average $43 \pm 8$ of the selected metabolites were detected in each sample (Supplementary Table S1 online). The full identification and chemical classification of the 72 selected metabolites can be found in the supplementary material (Supplementary Table S2 online).

The findings from the univariate and multivariate analyses are shown in Fig. 5 and Fig. 6. Results for the general Infection database, which included data points from both viral and bacterial challenges, can be seen in Fig. 5. Regardless of the causative agent, 11 metabolites were found to change significantly $(p<$ 0.05) compared to Baseline levels, where increases in 2-hydroxybutyrate, acetone, 3-hydroxyisobutyrate, and dimethyl sulfone, and decreases in succinylacetone, isobutyrate, 2-hydroxyvalerate, 0-acetylcholine, and isoleucine, allantoin, and ethanol, were observed. Examining the response to specific pathogenic agents revealed the concentrations of a subset of seven metabolites (BRSV $=2, \mathrm{MH}=5$ ) changed significantly $(p<0.05)$ compared to the Baseline (Fig. 6$)$. Infection with BRSV resulted in a significant $(p<$ 0.05 ) increase in guanidoacetate and a decrease in ethanol. On the other hand, infection with $M$. haemolytica showed significant $(p<0.05)$ increases in concentrations of 2-hydroxybutyrate, acetone, 3hydroxyisobutyrate, and $\pi$-methylhistidine, and a decrease in isobutyrate.

The PCA correlation loading plots revealed distinct metabolites influencing the patterns for each model (Fig. 7). The distribution of metabolites differentiating the Baseline model (Fig. 7a) was compared with the patterns from the three models of infection. In the model for the general infection (Fig. 7b), two metabolites (2-aminoadipate and saccharopine) were positively correlated, and 11 metabolites (lactate, galactitol, malonate, 3-hydroxy-3-methylglutarate, 3-hydroxybutyrate, trimethylamine $\mathrm{N}$-oxide, agmatine, alanine, N,N-dimethylglycine, and histamine) were negatively correlated when compared with the noninfected stage. In the PCA model for each pathogen, 35 metabolites (BRSV $=22, \mathrm{MH}=17$ ) changed in comparison to the Baseline model (Fig. 6). Of these 35 metabolites, only malonate, 3-hydroxy-3methylglutarate, leucine, and 2-aminoadipate changed in response to both pathogens (Fig. 6). In the PCA describing BRSV infection (Fig. 7c), 19 metabolites (malonate, 3-hydroxy-3-methylglutarate, leucine, betaine, histamine, creatine, creatine phosphate, creatinine, lactate, 3-hydroxybutyrate, acetate, trimethylamine $\mathrm{N}$-oxide, guanidoacetate, agmatine, alanine, dimethyl sulfone, formate, glycine, and N,Ndimethylglycine) were positively correlated. Only two metabolites (carnitine and cysteine) were negatively correlated in the BRSV infection. By contrast, in the M. haemolytica infection (Fig. 7d), nine metabolites were positively correlated (malonate, leucine, 2-aminoadipate, 4-aminobutyrate, $\mathrm{N}$-methylhydantoin, propionate, 5-aminolevulinate, isoleucine, and saccharopine), and eight metabolites were negatively correlated (3-hydroxy-3-methylglutarate, arabinitol, galactitol, glucose, 2-oxoglutarate, 2hydroxyisobutyrate, $\mathrm{N}$-acetylglycine, and valine).

\section{${ }^{1} \mathrm{H}$ - NMR Chemometrics-based multivariate analysis.}


The PCA scores plots showing the trends of the ${ }^{1} \mathrm{H}$ - NMR spectral signals can be seen in Fig. 8. In the scores plot, each point corresponds to either a Baseline or Infected sample, and overlap between the two groups indicates similarities in the metabolite composition of the blood plasma. Outliers are samples outside the confidence ellipse based on Hotelling's $T^{2}$ (significance level 0.05). The database for the general infection was analyzed with 10 principal components (Fig. 8a) giving modeling parameters $\mathrm{R}^{2} \mathrm{X}=$ 0.83 and $Q^{2}=0.56$; in this case, three outliers were identified, which corresponded to samples 33 (D9, calf 5), 34 (D11, calf 5), and 39 (D-2, calf 7). In the database of BRSV samples (Fig. 8b), 7 principal components gave a degree of optimization $\mathrm{R}^{2} \mathrm{X}=0.80$ and a cumulative prediction $\mathrm{Q}^{2}=0.38$, with two outliers: samples 22 (D4, calf 2) and 34 (D11, calf 5). In the database composed of M. haemolytica samples (Fig. 8c), 6 principal components produced modeling parameters $R^{2} X=0.79$ and a $Q^{2}=0.48$. The outlier corresponded to Baseline sample 39 (D -2, calf 7).

The OPLS - DA scores plots (Fig. 9) for the general infection (Fig. 9a), BRSV (Fig. 9c), and M. haemolytica (Fig. 6e) databases demonstrated a clear distinction in the chemistry of blood plasma from non-infected and infected cattle. This suggests that even though the chemical composition of the blood plasma is similar before and after infection, as shown in the PCA scores plots (Fig. 8), there is enough information to successfully detect and discriminate infection from baseline with an accuracy, sensitivity, and specificity higher than $95 \%$ (Table 2). More importantly, all the models showed a specificity of $100 \%$, meaning no false - positive samples (Baseline samples) were classified as infected. Table 2 shows the quality parameters for the calibrations and validations of each model using only two principal components (PCs). The values of $R^{2} X(>0.4), R^{2}(>0.9), R^{2} Y(>0.9)$, and $Q^{2}(>0.4)$ obtained in the calibration indicated that the models are robust, reliable, and have a low risk of overfitting ${ }^{41,49}$. In addition, $\mathrm{R}^{2}$ values were greater than $\mathrm{Q}^{2}$ in the permutation plots, such that a more positive slope in the regression line corresponds to a higher degree of fit to the data and the reliability of each model $41,42,44$. The distance to model plots and permutation plots for the discriminant models can be found in the Supplementary material files (Supplementary Figure S1 online). 
Table 2

OPLS - DA model quality parameters for the classification of ${ }^{1} \mathrm{H}$-NMR spectra from blood plasma collected before and after the controlled infections. Cal = calibration, $\mathrm{Val}=$ validation, $R^{2} X=$ degree of optimization, $R^{2}=$ coefficient of determination, $R^{2} Y=$ percentage of variation explained by the model, and $\mathrm{Q}^{2}=$ cumulative prediction, $\mathrm{t}[1] \mathrm{P}=$ first principal component.

\begin{tabular}{|c|c|c|c|}
\hline $\begin{array}{l}\text { OPLS - DA } \\
\text { MODELS }\end{array}$ & Baseline vs. Infected & Baseline vs. BRSV & $\begin{array}{l}\text { Baseline vs. } \\
\mathrm{MH}\end{array}$ \\
\hline$n$ & 70 & 40 & 30 \\
\hline Cal $R^{2} X$ & 0.67 & 0.39 & 0.45 \\
\hline Cal R ${ }^{2}$ & 0.94 & 0.96 & 0.94 \\
\hline Cal $R^{2} Y$ & 1.00 & 1.00 & 1.00 \\
\hline Cal Q ${ }^{2}$ & 0.65 & 0.81 & 0.75 \\
\hline $\begin{array}{l}\text { Accuracy } \\
(\%)\end{array}$ & 98.6 & 97.5 & 100 \\
\hline $\begin{array}{l}\text { Sensitivity } \\
(\%)\end{array}$ & 97.1 & 95 & 100 \\
\hline $\begin{array}{l}\text { Specificity } \\
(\%)\end{array}$ & 100 & 100 & 100 \\
\hline Val $R^{2}$ & 0.73 & 0.72 & 0.69 \\
\hline Val Q ${ }^{2}$ & -0.97 & -1.1 & -0.73 \\
\hline $\begin{array}{l}\text { Metabolites } \\
\text { contributing } \\
\text { to the } \\
\text { trends in } \\
\text { the scores } \\
\text { describing } \\
\text { Baseline } \\
\text { samples } \\
(\mathrm{t}[1] \mathrm{P}<0)\end{array}$ & $\begin{array}{l}\text { 3-hydroxybutyrate, } \\
\text { acetate, acetone, } \\
\text { alanine, allantoin, } \\
\text { glucose, glutamine, } \\
\text { histamine, isoleucine, } \\
\text { leucine, malonate, } \\
\text { methylamine, sarcosine, } \\
\text { tyrosine, urea, valine. }\end{array}$ & $\begin{array}{l}\text { acetate, acetoacetate, } \\
\text { acetone, allantoin, } \\
\text { creatine, creatinine, } \\
\text { glutamine, } \\
\text { guanidoacetate, } \\
\text { histamine, malonate, } \\
\text { methylamine, tyrosine, } \\
\text { urea. }\end{array}$ & $\begin{array}{l}\text { 3-hydroxybutyrate, acetate, } \\
\text { acetone, alanine, allantoin, } \\
\text { betaine, glucose, glutamine, } \\
\text { histamine, isoleucine, } \\
\text { leucine, malonate, } \\
\text { methylamine, N- } \\
\text { methylhydantoin, sarcosine, } \\
\text { tyrosine, urea, valine. }\end{array}$ \\
\hline $\begin{array}{l}\text { Metabolites } \\
\text { contributing } \\
\text { to the } \\
\text { trends in } \\
\text { the scores } \\
\text { describing } \\
\text { Infected } \\
\text { samples } \\
(\mathrm{t}[1] \mathrm{P}>0)\end{array}$ & $\begin{array}{l}\text { acetoacetate, creatine, } \\
\text { dimethyl sulfone, } \\
\text { formate, } \\
\text { guanidoacetate, lactate, } \\
\text { pyruvate, succinate, } \pi- \\
\text { methylhistidine. }\end{array}$ & $\begin{array}{l}\text { 3-hydroxybutyrate, } \\
\text { alanine, dimethyl } \\
\text { sulfone, formate, } \\
\text { glucose, isoleucine, } \\
\text { lactate, leucine, N- } \\
\text { methylhydantoin, } \\
\text { pyruvate, sarcosine, } \\
\text { succinate, valine, } \pi- \\
\text { methylhistidine. }\end{array}$ & $\begin{array}{l}\text { acetoacetate, creatine, } \\
\text { creatine phosphate, } \\
\text { creatinine, dimethyl sulfone, } \\
\text { formate, guanidoacetate, } \\
\text { lactate, pyruvate, succinate, } \\
\text { п-methylhistidine. }\end{array}$ \\
\hline
\end{tabular}


The color map derived from the coefficient loading plot indicates significant changes in spectral signals which contribute to the trends in the first principal component (t[1]P) of the OPLS - DA scores plot (Fig. 9) that distinguish Baseline from Infected samples. These spectral signals can be compared to known metabolite peaks, allowing them to be assigned in the loading plot. In Fig. 9, the peaks with positive values in the ${ }^{1} \mathrm{H}$ - NMR coefficient loading plot contribute to the trends in the scores describing Infected samples $(\mathrm{t}[1] \mathrm{P}>0)$, whereas metabolites with negative peaks contribute to the trends in the scores describing Baseline samples ( $\mathrm{t}[1] \mathrm{P}<0)$. Overall, similar trends in the coefficient loadings plots were observed for the general infection and the specific infection with $M$. haemolytica, and associated with the metabolites acetoacetate (ID = 15) and creatine. However, in the BRSV infection, these two metabolites were distinguishing contributions to Baseline classification (Table 2). In contrast, scores associated with BRSV infection have contributions from 3-hydroxybutyrate, alanine, glucose, isoleucine, leucine, Nmethylhydantoin, and valine. Yet, these same metabolites contribute to the scores for the Baseline samples from the M. haemolytica and the general Infection (Table 2). Overall, this suggests that there is potential to develop specific biochemical profiles for infection caused by the different main causal agents of BRD.

\section{Discussion}

In this study, ${ }^{1} \mathrm{H}$ - NMR was evaluated as a means to determine the metabolomics of BRD by detecting biomarkers in blood plasma after intentionally infecting dairy calves with the main causal agents of this disease under controlled conditions. The induced infections provided a larger and more accurate data set by including animals with limited or minor VCD signs but that were actually infected and metabolite information was verified with clinical physiological signs and hematological parameters recorded before and after the controlled infections. Similarly, the current blood plasma NMR - BRD metabolome, which was acquired in non-controlled field conditions ${ }^{33,34}$, used VCD as the reference method to determine the infection, however the lack of identification of specific causal agents restricted the discovery of specialized biomarkers that might be targeted for the development and validations of novel BRD management strategies such as NIRS-based diagnosis in the early stages of the disease. As a result, the current study adds to and expands on the existing metabolome by identifying unique biomarkers in cattle infected with BRSV and M. haemolytica independently.

Ruminants have a specialized digestive system to degrade grass and get the necessary nutrients to maintain homeostasis, and most of the glucose comes from the gluconeogenesis of oxaloacetate obtained from the propionate produced by the microorganism species Megasphaera, Veillonella, and Selenomonas in the rumen ${ }^{50,51}$. Because this is a slow process, supplying the energy demands during the cell signaling cascades and immune response caused by PAMPs recognition requires metabolism reprogramming by immune cells, where alternative energy sources such as triglycerides and proteins are used for ATP production ${ }^{52-54}$. Glucose is an upstream regulator of 26 genes associated with BRD, and if glucose homeostasis is disrupted, hypoglycemia or hyperglycemia occurs ${ }^{55}$. Decreases in glucose as observed in the present $M$. haemolytica challenge were previously reported in BRD studies as a result 
from natural or artificially induced infections, LPS injections, stress-related to transport, and receiving

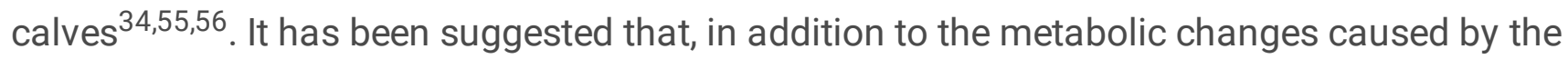
immunological response, the decrease in glucose levels is also due to the hypoglycemic effect of BRD and the decline in diet due to the discomfort caused by the respiratory signs ${ }^{34}$. Increases in glucose in response to viral infection, as shown in the BRSV challenge, are uncommon and have only been documented once in blood serum from cattle artificially infected with bovine herpesvirus type 1 (BHV - 1) and $M$. haemolytica ${ }^{57}$. This suggests that most of the known biochemical profiles for BRD, where glucose is reported to decrease and metabolites involved in ketosis appear to increase, could be primarily associated with the secondary bacterial infection characteristic of this disease.

To meet the energy demands due to the recruitment of inflammatory cells and the phagocytotic processes for microbial death, immune cells such as neutrophils, monocytes, macrophages, and lymphocytes undergo aerobic glycolysis ${ }^{53,54}$. In this scenario, pyruvate does not enter the mitochondrion but is instead metabolized to lactate in the cytoplasm, with glycolysis rapidly providing minor amounts of ATP $^{52,53}$. Lactate increases were detected only during the BRSV challenge. Similarly, cattle that died from a combination of BHV - 1 and $M$. haemolytica infection had higher lactate concentrations than those that survived ${ }^{57}$. It has been reported that the decrease in oxygen levels during BRD due to stress, blockage of the respiratory tract with mucous secretions, and lung affection also increased lactate concentration, the likelihood of disease progression, and eventual mortality in dairy cattle ${ }^{58}$. Aerobic metabolism in neutrophils is associated with an increase in reactive oxygen species (ROS), an important source of bactericidal activity ${ }^{53}$. Increases in 2-hydroxybutyrate, which is a metabolite associated with ROS production and lipid oxidation (ß-oxidation), was detected here in the M. haemolytica infection and has been previously linked to diabetes, as well as being a predictor of insulin and glucose resistance, causing proinflammatory responses and increased oxidative stress ${ }^{59,60}$.

To offset the consequences of metabolic diseases involving energy imbalance, ruminants and, more specifically, bovine species are known to use the alternative triglyceride route ${ }^{27-30,32}$. Triglycerides are made up of glycerol and fatty acids. Fatty acids undergo ß-oxidation in the liver, producing acetyl - CoA, which enters the Tricarboxylic acid (TCA) cycle. As a result, the reducing agents $\mathrm{NADH}$ and $\mathrm{FADH}_{2}$ are produced, which feed the electron transport chain (ETC) and drive large amounts of ATP production to address energy imbalance ${ }^{53,61}$. Large amounts of acetyl - CoA exceeding the capacity of the TCA cycle result in the generation of ketone bodies ${ }^{52,61}$. During $B R D$, glucose and oxygen uptake are reduced, resulting in increased ketone body formation ${ }^{62,63}$. Under such conditions, the metabolites 3 hydroxybutyrate, acetoacetate, and acetone form downstream of acetyl - CoA generation ${ }^{62,64}$. Increases in 3-hydroxybutyrate as detected here in the BRSV challenge had been reported as important for differentiating healthy from sick cattle with $\mathrm{BRD}^{34}$ and have a negative effect on neutrophil function and recruitment, consequently allowing pneumonia to progress ${ }^{65}$. Here, increases of the ketone bodies acetone and acetoacetate, and the dicarboxylic acids malonate and 3-hydroxy-3-methylglutarate were detected in dairy calves infected with $M$. haemolytica. Taken together, these results support the idea that 
higher energy supplies, derived from fatty acid pathways, could be required to counteract the energy imbalance caused by the immune response to the secondary bacterial infection rather than the initial viral infection.

The alternative protein pathway is the final resource used to overcome increased metabolic demands ${ }^{66}$. Changes in the concentrations of glucogenic amino acids, ketogenic amino acids, and their metabolites were detected during both controlled infections as previously observed in cattle with ketosis caused by negative energy balance ${ }^{67}$. Here, a decrease of the alpha-amino acid 2-aminoadipate was detected in response to both pathogens. This metabolite is an intermediate in the metabolism of the ketogenic amino acid lysine ${ }^{25}$. During the BRSV challenge, changes in the concentration of the alpha-amino acids creatine, creatine phosphate, and creatinine, and the imidazoline N-methylhydantoin suggested that BRSV could be causing viral myositis, affecting muscle health by increasing the metabolites involved in the regeneration of ATP in skeletal muscle to energize muscle contraction ${ }^{68}$. In the controlled infection with M. haemolytica, the glucogenic amino acid valine decreased, while isoleucine which can be glucogenic or ketogenic increased. In contrast, previous research demonstrated that injecting LPS from M. haemolytica into feed cattle reduced the levels of isoleucine in blood plasma while increasing alanine ${ }^{69,70}$.

In this work, chemometric-based MVA successfully distinguished the ${ }^{1} \mathrm{H}$ - NMR spectra from bovine blood plasma collected during the Baseline and Infected stages of both challenge studies with an accuracy, sensitivity, and specificity $\geq 95 \%$, which is greater than the $65 \%$ found in $\operatorname{VCD}^{15,16}$ and similar to the threshold reached by transthoracic ultrasound evaluation and serological and molecular techniques used in the diagnosis of infection ${ }^{71-73}$. These findings indicate biochemical differences between healthy and sick animals with the main causal agents of BRD, where metabolites related to homeostasis in the baseline and energy imbalance during the infections were found to influence the discrimination plots. Previous research using NIRS and NMR also successfully discriminated blood plasma from cattle infected with BRD, with sensitivities and specificities close to $90 \%$ when using VCD as reference method $19,33,34$. The findings in the current study are also consistent with previous research that used discriminant analysis on NMR spectra of blood plasma from cattle to identify the metabolomics of animals with ketosis, ovarian quiescence, and fatty liver disorder ${ }^{27,29-32}$ showing the potential of this technique for the detection of metabolic disorders related with nutrition, reproduction, and disease.

\section{Conclusion}

By using ${ }^{1} \mathrm{H}$ - NMR spectroscopy in blood plasma, this study demonstrated that important metabolic shifts are occurring in the host in response to infection with BRSV or M. haemolytica. Following the application of univariate and multivariate statistical methods, the concentration of 42 metabolites (BRSV $=27, \mathrm{MH}=24)$ changed in comparison to the Baseline stage. These metabolites appeared to be critical fuel substrates and products of the energy imbalance occurring during the infections due to signaling cascades and immune response activation. In addition, our findings support the potential of NMR to 
create metabolic profiles of BRD that contribute to the understanding of the diversity and concentrations of essential metabolites in blood plasma that can be used for further development of diagnostic tools.

\section{Declarations}

\section{Acknowledgments}

The authors thank Victoria Jefferson, Amanda Free, Hannah Bostick, Matt Harjes, and Dr. Matt Scott (D.V.M) for their help during the blood sample collection and preparation. This project was supported by the Mississippi Agricultural and Forestry Experiment Station, the National Institute of Food and Agriculture, U.S. Department of Agriculture, Hatch project under accession number W3173, the USDA ARS Biophotonics Initiative grant \# 58 - 6402 - 018, the National Science Foundation grant \# MCB1818090, and The National Institutes of Health grant \# R01Al139479 and \# P20GM103646. The funding sources played no role in the study design, data collection, data analysis and interpretation, manuscript writing, or manuscript submission for publication.

\section{Author contributions}

M.S.R. was involved in the research conceptualization, funding acquisition, and resources, supervised the sample collection, carried out the ${ }^{1} \mathrm{H}$ - NMR experiments, data collection, data curation, formal data analysis and validation of results, manuscript visualization, design, and writing. N.C.F. led the ${ }^{1} \mathrm{H}-\mathrm{NMR}$ experiments and provided resources. R.A.H. supervised the ${ }^{1} \mathrm{H}$ - NMR experiments. R.E.B. performed the ${ }^{1} \mathrm{H}$ - NMR experiments, data curation and contributed to the literature review. E.B. sample and ${ }^{1} \mathrm{H}$ - NMR data collection and curation. M.T. collected samples and VCD data. A.R.W. was involved in the research conceptualization, funding acquisition, supervision of animal experiments, and data collection. F.M. participated in research conceptualization, experimental design, funding acquisition, and resources. C.K.V. was in charge of the research conceptualization, experimental design, funding acquisition, supervision, resources, and manuscript visualization and editing. All authors contributed to the final review and editing of the manuscript and have given their approval for submission.

\section{Competing interests}

The author(s) declare no competing interests with respect to the research, authorship, and/or publication of this article.

\section{Data availability}

Data is available upon request from Carrie K. Vance (ckv7@msstate.edu). 


\section{References}

1. Snowder, G. D., Van Vleck, L. D., Cundiff, L. V. \& Bennett, G. L. Bovine respiratory disease in feedlot cattle: Environmental, genetic, and economic factors. J. Anim. Sci, 84, 1999-2008 (2006).

2. Klima, C. L. et al. Pathogens of bovine respiratory disease in North American feedlots conferring multidrug resistance via integrative conjugative elements. J. Clin. Microbiol, 52, 438-448 (2014).

3. Urban-Chmiel, R. \& Grooms, D. Prevention and control of bovine respiratory disease. J. Livest. Sci, 3, 27-36 (2012).

4. Dubrovsky, S. A. et al. Preweaning cost of bovine respiratory disease (BRD) and cost-benefit of implementation of preventative measures in calves on California dairies: The BRD 10K study. J. Dairy Sci, 103, 1583-1597 (2020).

5. Amat, S. Bovine Respiratory Disease in Feedlot Cattle: Antimicrobial resistance in bovine respiratory bacterial pathogens and alternative antimicrobial approaches. IntechOpen i, 38(2012).

6. Valarcher, J. F. \& Taylor, G. Bovine respiratory syncytial virus infection. Vet. Res, 38, 153-180 (2007).

7. Guzman, E. \& Taylor, G. Immunology of bovine respiratory syncytial virus in calves. Mol. Immunol, 66, 48-56 (2015).

8. Taylor, J. D., Fulton, R. W., Lehenbauer, T. W., Step, D. L. \& Confer, A. W. The epidemiology of bovine respiratory disease: What is the evidence for predisposing factors? Can. Vet. J, 51, 1095-1102 (2010).

9. Bell, R. L., Turkington, H. L. \& Cosby, S. L. The bacterial and viral agents of BRDC: Immune evasion and vaccine developments. Vaccines, 9, 1-18 (2021).

10. Gasteiger, G. et al. Cellular innate immunity: An old game with new players. J. Innate Immun, 9, 111125 (2017).

11. Werling, D. \& Coffey, T. J. Pattern recognition receptors in companion and farm animals - The key to unlocking the door to animal disease? Vet. J, 174, 240-251 (2007).

12. McGill, J. L. \& Sacoo, R. E. The immunology of bovine respiratory disease. Vet Clin Food Anim, 36, 333-348 (2020).

13. Singh, K., Ritchey, J. W. \& Confer, A. W. Mannheimia haemolytica: Bacterial-host interactions in bovine Pneumonia. Vet. Pathol, 48, 338-348 (2011).

14. Fulton, R. W. \& Confer, A. W. Laboratory test descriptions for bovine respiratory disease diagnosis and their strengths and weaknesses: Gold standards for diagnosis, do they exist? Can. Vet. J, 53, 754761 (2012).

15. White, B. J. et al. Bayesian evaluation of clinical diagnostic test characteristics of visual observations and remote monitoring to diagnose bovine respiratory disease in beef calves. Prev. Vet. Med, 126, 74-80 (2016).

16. Timsit, E., Dendukuri, N., Schiller, I. \& Buczinski, S. Diagnostic accuracy of clinical illness for bovine respiratory disease (BRD) diagnosis in beef cattle placed in feedlots: A systematic literature review and hierarchical Bayesian latent-class meta-analysis. Prev. Vet. Med, 135, 67-73 (2016). 
17. Goldansaz, S. A. et al. Livestock metabolomics and the livestock metabolome: A systematic review. PLoS One, 12, 1-26 (2017).

18. Pontes, J. G. M., Brasil, A. J. M., Cruz, G. C. F., De Souza, R. N. \& Tasic, L. NMR-based metabolomics strategies: plants, animals and humans. Anal. Methods, 9, 1078-1096 (2017).

19. Santos-Rivera, M. et al. Profiling Mannheimia haemolytica infection in dairy calves using near infrared spectroscopy (NIRS) and multivariate analysis (MVA). Sci. Rep, 1-13 https://doi.org/10.1038/s41598-021-81032-x (2021).

20. Manchester, M., Anand, A. \& Metabolomics Strategies to Define the Role of Metabolism in Virus Infection and Pathogenesis. Adv. Virus Res, 98, 57-81 (2017).

21. Hill, R. A. et al. Effect of Biochar on Microbial Growth: A Metabolomics and Bacteriological Investigation in E. coli. Environ. Sci. Technol, 53, 2635-2646 (2019).

22. Burcham, L. R. et al. Streptococcus pneumoniae metal homeostasis alters cellular metabolism. Metallomics, 12, 1416-1427 (2020).

23. Gerothanassis, I. P., Troganis, A., Exarchou, V. \& Barrbarossou, K. Nuclear Magnetic Resonance (NMR) Spectroscopy: Basic principles and phenomena, and their applications to chemistry, biology and medicine. Chem. Educ. Res. Pr, 3, 229-252 (2002).

24. Emwas, A. H. et al. NMR spectroscopy for metabolomics research.Metabolites9, (2019).

25. Foroutan, A. et al. The bovine metabolome. Metabolites, 10, 1-26 (2020).

26. Duarte, R. T., Simões, C., Sgarbieri, V. C. \& M. C. \& Bovine blood components: Fractionation, composition, and nutritive value. J. Agric. Food Chem, 47, 231-236 (1999).

27. Zhang, J. et al. 1H NMR Plasma Metabolomic Profiling of Ovarian Quiescence in Energy Balanced Postpartum Dairy Cows. Vet. Q, 38, 47-52 (2018).

28. Klein, M. S. et al. NMR metabolomic analysis of dairy cows reveals milk glycerophosphocholine to phosphocholine ratio as prognostic biomarker for risk of ketosis. J. Proteome Res, 11, 1373-1381 (2012).

29. Sun, L. W. et al. 1H-Nuclear magnetic resonance-based plasma metabolic profiling of dairy cows with clinical and subclinical ketosis. J. Dairy Sci, 97, 1552-1562 (2014).

30. Ying Li, C. X. 1H NMR-based Plasma Metabolic Profiling of Dairy Cows with Type I and Type II Ketosis. Pharm. Anal. Acta06, (2015).

31. Wang, Y. et al. Pathway analysis of plasma different metabolites for dairy cow ketosis. Ital. J. Anim. Sci, 15, 545-551 (2016).

32. $\mathrm{Xu}, \mathrm{C}$. et al. $1 \mathrm{H}-$ Nuclear magnetic resonance-based plasma metabolic profiling of dairy cows with fatty liver. Asian-Australasian J. Anim. Sci, 29, 219-229 (2016).

33. Basoglu, A., Baspinar, N., Tenori, L., Vignoli, A. \& Yildiz, R. Plasma metabolomics in calves with acute bronchopneumonia., 12, 1-10 (2016).

34. Blakebrough-Hall, C., Dona, A., D’occhio, M. J., McMeniman, J. \& González, L. A. Diagnosis of Bovine Respiratory Disease in feedlot cattle using blood 1H NMR metabolomics. Sci. Rep, 10, 1-12 (2020). 
35. Dona, A. C. et al. Precision high-throughput proton NMR spectroscopy of human urine, serum, and plasma for large-scale metabolic phenotyping. Anal. Chem, 86, 9887-9894 (2014).

36. Adams, R. W., Holroyd, C. M., Aguilar, J. A., Nilsson, M. \& Morris, G. A. "Perfecting" WATERGATE: Clean proton NMR spectra from aqueous solution. Chem. Commun, 49, 358-360 (2013).

37. Kostidis, S., Addie, R. D., Morreau, H., Mayboroda, O. A. \& Giera, M. Quantitative NMR analysis of intraand extracellular metabolism of mammalian cells: A tutorial. Anal. Chim. Acta, 980, 1-24 (2017).

38. Wishart, D. S. et al. The human metabolome database. Nucleic Acids Res. 35, HMDB, 521-526 (2007).

39. Barton, R. H. et al. The influence of EDTA and citrate anticoagulant addition to human plasma on information recovery from NMR-based metabolic profiling studies. Mol. Biosyst, 6, 215-224 (2009).

40. Monakhova, Y. B., Kuballa, T., Tschiersch, C. \& Diehl, B. W. K. Rapid NMR determination of inorganic cations in food matrices: Application to mineral water. Food Chem, 221, 1828-1833 (2017).

41. Worley, B. \& Powers, R. Multivariate Analysis in Metabolomics. Curr. Metabolomics, 1, 92-107 (2013).

42. Trygg, J., Holmes, E. \& Lundstedt, T. Chemometrics in metabonomics. J. Proteome Res, 6, 469-479 (2007).

43. Wong, H. B. \& Lim, G. H. Measures of diagnostic accuracy: Sensitivity, specificity, PPV and NPV. Proc. Singapore Healthc. 20, 316-318(2011).

44. Westerhuis, J. A. et al. Assessment of PLSDA cross validation., 4, 81-89 (2008).

45. Theurer, M. E. et al. Effect of Mannheimia haemolytica pneumonia on behavior and physiologic responses of calves during high ambient environmental temperatures. J. Anim. Sci, 91, 3917-3929 (2013).

46. Gioia, J. et al. The genome sequence of Mannheimia haemolytica A1: Insights into virulence, natural competence, and Pasteurellaceae phylogeny. J. Bacteriol, 188, 7257-7266 (2006).

47. Jollife, I. T. \& Cadima, J. Principal component analysis: A review and recent developments.Philos. Trans. R. Soc. A Math. Phys. Eng. Sci.374, (2016).

48. Mwove, J. K., Gogo, L. A., Chikamai, B. N., Omwamba, M. \& Mahungu, S. M. Principal component analysis of physicochemical and sensory characteristics of beef rounds extended with gum arabic from Acacia senegal var. kerensis. Food Sci. Nutr, 6, 474-482 (2018).

49. Wang, H. et al. A Diet Diverse in Bamboo Parts is Important for Giant Panda (Ailuropoda melanoleuca) Metabolism and Health. Sci. Rep, 7, 1-13 (2017).

50. Niwiska, B. Digestion in Ruminants. Carbohydrates - Compr. Stud. Glycobiol. Glycotechnol, https://doi.org/10.5772/51574 (2012).

51. Pérez-Barbería, F. J. The Ruminant: Life history and digestive physiology of a symbiotic animal. SpringerBriefs Appl. Sci. Technol, 19-45 https://doi.org/10.1007/978-3-030-46060-0_2 (2020).

52. Eisenreich, W., Rudel, T., Heesemann, J. \& Goebel, W. How viral and intracellular bacterial pathogens reprogram the metabolism of host cells to allow their intracellular replication.Front. Cell. Infect. 
Microbiol.9, (2019).

53. Gleeson, L. E. \& Sheedy, F. J. Metabolic reprogramming \& inflammation: Fuelling the host response to pathogens. Semin. Immunol, 28, 450-468 (2016).

54. Kominsky, D. J., Campbell, E. L. \& Colgan, S. P. Metabolic Shifts in Immunity and Inflammation. J Immunol, 184, 4062-4068 (2010).

55. Devant, M. \& Marti, S. Strategies for feeding unweaned dairy beef cattle to improve their health. Animals, 10, 1-20 (2020).

56. Montgomery, S. P. et al. Plasma metabolites of receiving heifers and the relationship between apparent bovine respiratory disease, body weight gain, and carcass characteristics. J. Anim. Sci, 87, 328-333 (2009).

57. Aich, P., Babiuk, L. A., Potter, A. A. \& Griebel, P. Biomarkers for prediction of bovine respiratory disease outcome. Omi. A J. Integr. Biol, 13, 199-209 (2009).

58. Coghe, J. et al. Validation and prognostic value of plasma lactate measurement in bovine respiratory disease. Vet. J, 160, 139-146 (2000).

59. Gall, W. E. et al. A-Hydroxybutyrate is an early biomarker of insulin resistance and glucose intolerance in a nondiabetic population. PLoS One5, (2010).

60. Ferrannini, E. et al. Early metabolic markers of the development of dysglycemia and type 2 diabetes and their physiological significance., 62, 1730-1737 (2013).

61. Alves-Bezerra, M. \& Cohen, D. E. Triglyceride metabolism in the liver. Compr. Physiol, 8, 1-22 (2018).

62. Hillreiner, M., Flinspach, C., Pfaffl, M. W. \& Kliem, H. Effect of the ketone body beta-hydroxybutyrate on the innate defense capability of primary bovine mammary epithelial cells. PLoS One, 11, 1-18 (2016).

63. Sato, H. Increased blood concentration of isopropanol in ketotic dairy cows and isopropanol production from acetone in the rumen. Anim. Sci. J, 80, 381-386 (2009).

64. Sato, H. \& Shiogama, Y. Acetone and isopropanol in ruminal fluid and feces of lactating dairy cows. J. Vet. Med. Sci, 72, 297-300 (2010).

65. Caswell, J. L. Failure of respiratory defenses in the pathogenesis of bacterial pneumonia of cattle. Vet. Pathol, 51, 393-409 (2014).

66. Reeds, P. J. \& Jahoor, F. The amino acid requirements of disease. Clin. Nutr, 20, 15-22 (2001).

67. Marczuk, J., Brodzki, P., Brodzki, A. \& Kurek The concentration of free amino acids in blood serum of dairy cows with primary ketosis. Pol. J. Vet. Sci, 21, 149-156 (2018).

68. Crum-Cianflone, N. F. Bacterial, fungal, parasitic, and viral myositis. Clin. Microbiol. Rev, 21, 473-494 (2008).

69. Waggoner, J. W., Löest, C. A., Mathis, C. P., Hallford, D. M. \& Petersen, M. K. Effects of rumen-protected methionine supplementation and bacterial lipopolysaccharide infusion on nitrogen metabolism and hormonal responses of growing beef steers. J. Anim. Sci, 87, 681-692 (2009). 
70. Waggoner, J. W., Löest, C. A., Turner, J. L., Mathis, C. P. \& Hallford, D. M. Effects of dietary protein and bacterial lipopolysaccharide infusion on nitrogen metabolism and hormonal responses of growing beef steers. J. Anim. Sci, 87, 3656-3668 (2009).

71. Berman, J., Francoz, D., Dufour, S. \& Buczinski, S. Bayesian estimation of sensitivity and specificity of systematic thoracic ultrasound exam for diagnosis of bovine respiratory disease in pre-weaned calves. Prev. Vet. Med, 162, 38-45 (2019).

72. Wolfger, B., Timsit, E., White, B. J. \& Orsel, K. A. Systematic Review of Bovine Respiratory Disease Diagnosis Focused on Diagnostic Confirmation, Early Detection, and Prediction of Unfavorable Outcomes in Feedlot Cattle. Vet. Clin. North Am. Food Anim. Pract, 31, 351-365 (2015).

73. Cornelissen, J. B. W. J. et al. Mycoplasma detection by triplex real-time PCR in bronchoalveolar lavage fluid from bovine respiratory disease complex cases. BMC Vet. Res, 13, 1-12 (2017).

\section{Figures}

a)

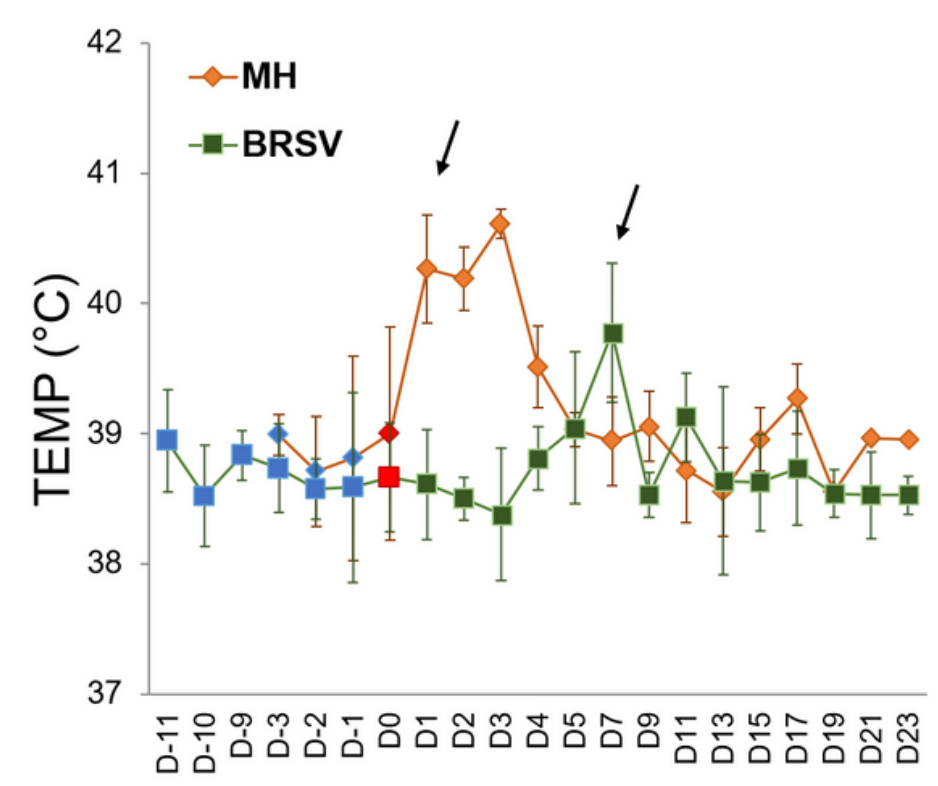

Day of sample collection b)

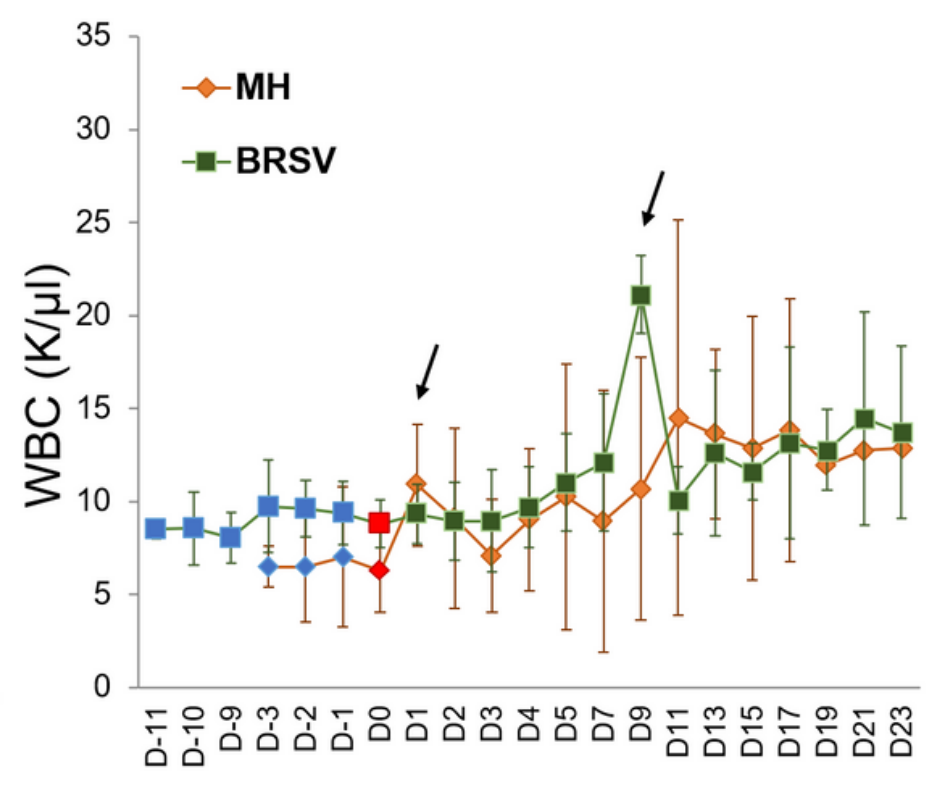

Day of sample collection

\section{Figure 1}

Dairy calves' responses to viral $(n=5)$ and bacterial $(n=5)$ infection. Calves were challenged with the infectious agent on D0. (a) Daily rectal temperature (TEMP, ${ }^{\circ} \mathrm{C}$ ) displayed as Mean $\pm \mathrm{SD}$. (b) WBC (thousands per cubic milliliter, $\mathrm{K} / \mu \mathrm{l}$ ) presented as Mean $\pm \mathrm{SD}$. A characteristic increase after signs of disease (indicated by arrows) in each challenge can be seen due to the activation of nonspecific defense mechanisms against BRSV and $\mathrm{M}$. haemolytica $(\mathrm{MH})$ virulence factors. Markers in blue are the Baseline days; the red markers point to the day of the pathogenic challenge. 
Analysis

Baseline

$(\mathbf{n}=\mathbf{5 5})$
Infected with Infected with

\begin{tabular}{cc}
$\begin{array}{c}\text { BRSV } \\
(n=21)\end{array}$ & $\begin{array}{c}\text { MH } \\
(n=26)\end{array}$ \\
\hline
\end{tabular}

Prob $>$ F

\section{Visual-clinical diagnosis (VCD)}

\begin{tabular}{|c|c|c|c|c|}
\hline Temperature $\left({ }^{\circ} \mathrm{C}\right)$ & $38.7 \pm 0.4 \mathbf{B}$ & $39.0 \pm 0.7 \mathbf{B}$ & $40.2 \pm 0.9 \mathbf{A}$ & 0.0001 \\
\hline Respiratory rate per minute & $25.5 \pm 10.8 \mathrm{C}$ & $52.6 \pm 22.8 \mathbf{B}$ & $82.1 \pm 19.6 \mathbf{A}$ & 0.000 \\
\hline Heart rate per minute & $91.5 \pm 10.7$ & $92.5 \pm 11.5$ & $98.9 \pm 15.4$ & 0.135 \\
\hline \multicolumn{5}{|c|}{ Complete blood counts (CBC) } \\
\hline Red blood cell count $(\mathrm{M} / \mu \mathrm{l})$ & $8.6 \pm 0.9 \mathrm{~B}$ & $9.9 \pm 2.6 \mathbf{A}$ & $7.6 \pm 0.8 \mathrm{~B}$ & 0.0002 \\
\hline Hemoglobin $(\mathrm{g} / \mathrm{dl})$ & $10.6 \pm 0.6$ & $11.2 \pm 2.4$ & $10.1 \pm 1.0$ & 0.120 \\
\hline Hematocrit (\%) & $30.3 \pm 4.4 \mathbf{B}$ & $32.8 \pm 2.2 \mathbf{A}$ & $27.7 \pm 2.4 \mathrm{C}$ & 0.0003 \\
\hline Platelets $(\mathrm{K} / \mu \mathrm{l})$ & $650 \pm 194 \mathbf{B}$ & $758 \pm 198 \mathbf{A , B}$ & $822 \pm 230 \mathbf{A}$ & 0.017 \\
\hline White blood cell count $(\mathrm{K} / \mu \mathrm{l})$ & $8.2 \pm 2.1 \mathbf{B}$ & $12.8 \pm 5.5 \mathrm{~A}$ & $10.1 \pm 4.1 \mathrm{~A}, \mathbf{B}$ & 0.000 \\
\hline Neutrophils (\%) & $33.9 \pm 8.5 \mathbf{B}$ & $47.8 \pm 19.2 \mathbf{A}$ & $40.3 \pm 179 \mathbf{A}, \mathbf{B}$ & 0.004 \\
\hline Lymphocytes (\%) & $41.1 \pm 11.2 \mathbf{A}$ & $30.8 \pm 18.0 \mathbf{B}$ & $34.0 \pm 17.0 \mathbf{A}, \mathbf{B}$ & 0.038 \\
\hline Eosinophils (\%) & $0.9 \pm 1.2 \mathrm{~A}$ & $0.2 \pm 0.5 \mathbf{B}$ & $0.6 \pm 1.1 \mathbf{A}, \mathbf{B}$ & 0.042 \\
\hline Basophils (\%) & $1.7 \pm 1.3 \mathbf{A}$ & $0.7 \pm 0.8 \mathbf{B}$ & $1.1 \pm 1.8 \mathbf{A}, \mathbf{B}$ & 0.013 \\
\hline Monocytes (\%) & $22.4 \pm 9.4$ & $20.7 \pm 7.8$ & $23.9 \pm 12.3$ & 0.607 \\
\hline
\end{tabular}

Figure 2

Visual clinical diagnosis and hematological values (Mean \pm SD) for dairy calves challenged with BRSV and $M$. haemolytica $(\mathrm{MH})$. For the ANOVA, values with different letters were significantly different $(\mathrm{p}<$ 0.05) between categories, with a significant increase (dark purple) or decrease (dark yellow) compared to the Baseline. Values positively correlated in the PCA during infection (light purple) compared with the Baseline. Prob $>\mathrm{F}=\mathrm{p}$-value for the whole model test, Italic = parameter changed in the ANOVA and the $\mathrm{PCA}, \mathrm{M} / \mu \mathrm{l}=$ Millions per microliter, $\mathrm{g} / \mathrm{dl}=$ grams per deciliter, $\mathrm{K} / \mu \mathrm{l}=$ thousands per cubic milliliter . 

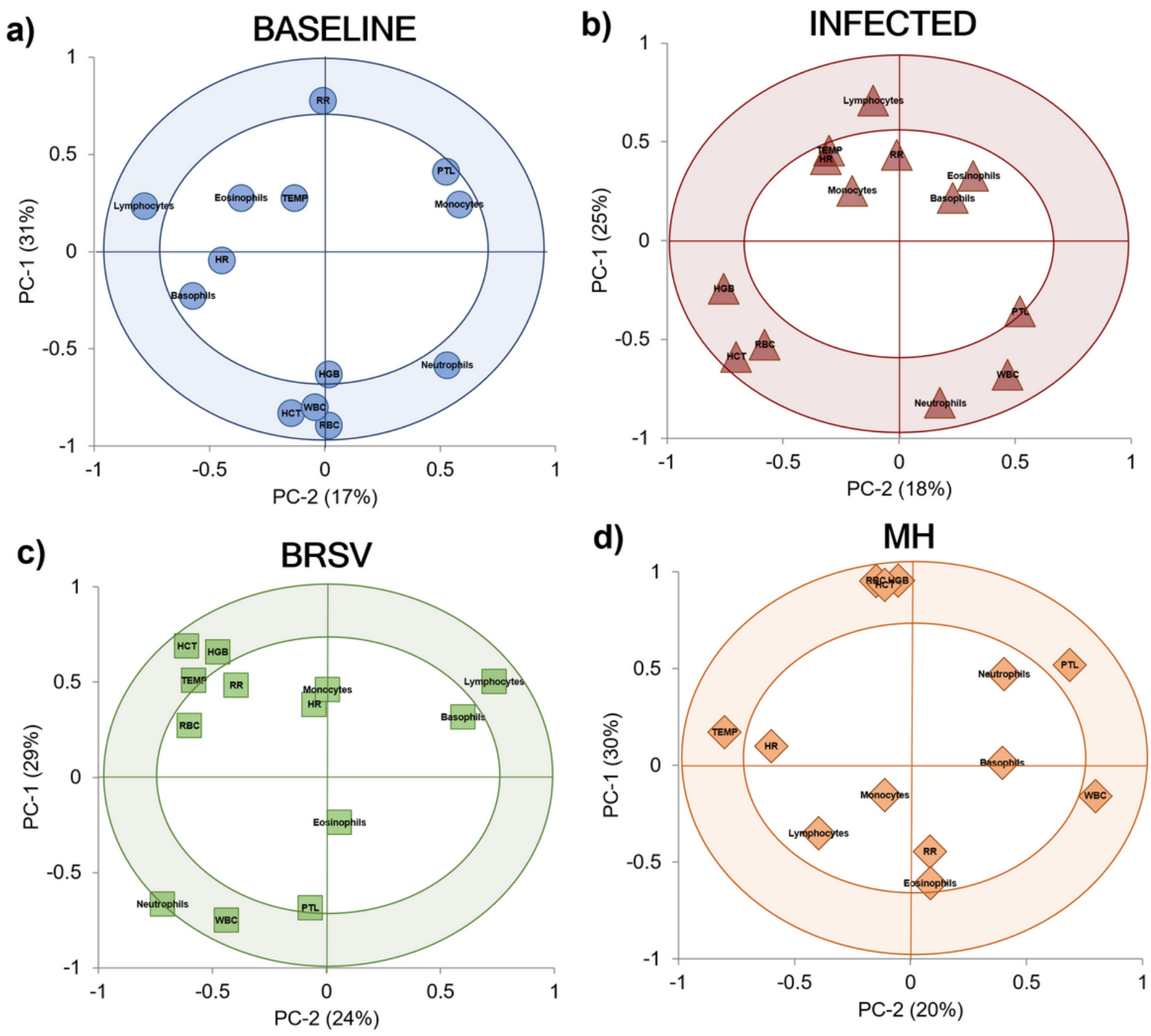

\section{Figure 3}

Principal component analysis (PCA) correlation loadings plots for visual-clinical diagnosis (VCD) and complete blood counts ( $\mathrm{CBC}$ ). The variables inside the outer circle (colored area) have the most influence on database variability and are positively or negatively correlated within each model, while the parameters within the inner circle have low or no influence. (a) Baseline $(n=55)$; two PCs explained $48 \%$ of the variance. (b) Infected $(n=47)$ combined data from both studies, two PCs explained $43 \%$ of the variation of the database. (c) Infected with BRSV ( $n=21)$, two PCs explained $53 \%$ of the variation of the database. (d) Infected with M. haemolytica $(\mathrm{MH})(\mathrm{n}=26)$, two PCs explained $50 \%$ of the variation of the database. 


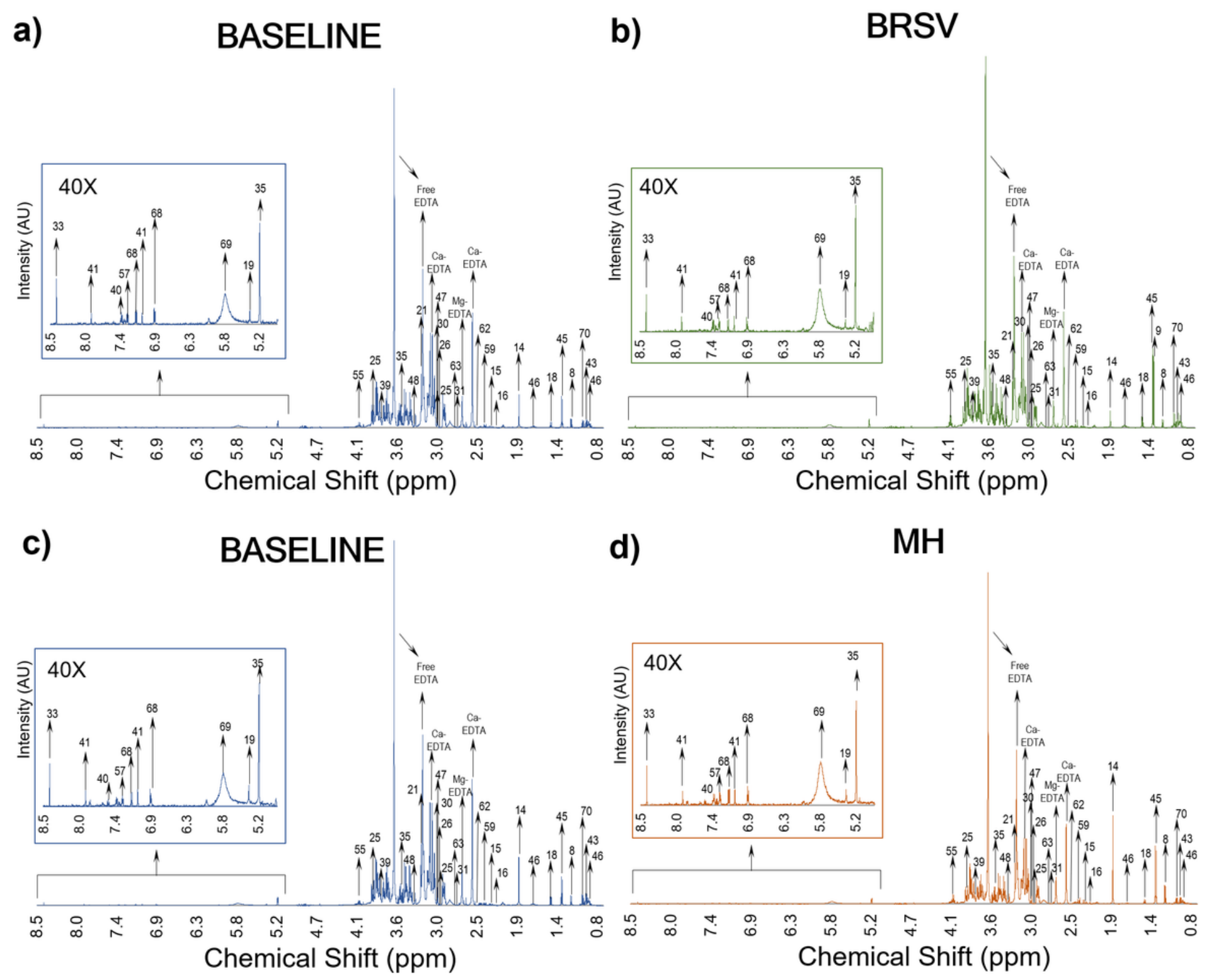

Figure 4

1H-NMR spectra (0.8 - $9.0 \mathrm{ppm})$ showing the peak intensities of metabolites present in blood plasma after the controlled infections with the main causal agents of BRD. (a) BRSV sample 66 (D0, calf 4), (b) BRSV sample 29 (D9, calf 4), (c) M. haemolytica (MH) sample 38 (D0, calf 6), (d) MH sample 2 (D2, calf 6). To improve the visualization of the peaks, the size of the region between $5.1-8.5 \mathrm{ppm}$ was increased $40 \mathrm{x}$. 


\begin{tabular}{|c|c|c|c|c|c|c|}
\hline${ }^{1}$ H-NMR Metabolite & ID & Baseline & Infected & Prob $>$ F & $\begin{array}{c}\text { Chemical } \\
\text { classification }\end{array}$ & Biochemical pathways \\
\hline Lactate & 45 & $0.521 \pm 0.316$ & $0.706 \pm 0.632$ & 0.128 & $\begin{array}{l}\text { Alph a hydroxy acids } \\
\text { and derivatives }\end{array}$ & Glucose metabolism \\
\hline Galactitol & 34 & $0.031 \pm 0.031$ & $0.024 \pm 0.023$ & 0.291 & Sugar alcoh ol & Galactose metabolism \\
\hline Succinylacetone & 63 & $0.021 \pm 0.024$ & $0.011 \pm 0.008^{*}$ & 0.022 & $\begin{array}{l}\text { Medium-chain keto } \\
\text { acids and derivatives }\end{array}$ & Glucose metabolism. Glycine and tyrosine metabolism \\
\hline 2-Hydroxybutyrate & 3 & $0.003 \pm 0.005$ & $0.007 \pm 0.010^{*}$ & 0.036 & $\begin{array}{l}\text { Alpha hydroxy acids } \\
\text { and derivatives }\end{array}$ & Fatty acid biosyn thesis. TCA cycle \\
\hline Isobutyrate & 42 & $0.009 \pm 0.008$ & $0.004 \pm 0.006^{*}$ & 0.008 & Carboxylic acid & Branched fatty acid \\
\hline 2-Hydroxyvalerate & 5 & $0.022 \pm 0.039$ & $0.005 \pm 0.012^{*}$ & 0.019 & Hydroxy fatty acid & Fatty acid bios yn thesis \\
\hline Malonate & 47 & $1.755 \pm 0.576$ & $2.037 \pm 1.049$ & 0.167 & $\begin{array}{l}\text { Dicarboxylic acids } \\
\text { and derivatives }\end{array}$ & Fatty acid bios yn thesis \\
\hline Acetone & 16 & $0.005 \pm 0.003$ & $0.009 \pm 0.008^{*}$ & 0.008 & Ketone & Ketone Bodies Metabolism \\
\hline 3-Hydroxy-3-methylglutarate & 7 & $0.012 \pm 0.018$ & $0.020 \pm 0.052$ & 0.381 & $\begin{array}{l}\text { Dicarboxylic acids } \\
\text { and derivatives }\end{array}$ & Ketone bodies and leucine metabolis $m$ \\
\hline 3-Hydroxybutyrate & 8 & $0.094 \pm 0.090$ & $0.148 \pm 0.230$ & 0.203 & $\begin{array}{l}\text { Beta hydroxy acids } \\
\text { and derivatives }\end{array}$ & Ketone bodies metabolis m. Fatty acid bios yn the $s$ is \\
\hline Trimethylamine N-oxide & 67 & $0.128 \pm 0.050$ & $0.130 \pm 0.097$ & 0.899 & Trialkyl amine oxide & Ch olesterol m etabolism \\
\hline O-Acetylcholine & 56 & $0.005 \pm 0.005$ & $0.002 \pm 0.003^{*}$ & 0.014 & Acyl choline & Ph os ph olip id bios yn thesis \\
\hline 3-Hydroxyisobutyrate & 9 & $0.002 \pm 0.007$ & $0.008 \pm 0.012^{*}$ & 0.015 & $\begin{array}{l}\text { Beta hydroxy acids } \\
\text { and derivatives }\end{array}$ & Metabolism of the glucogenic am in o acid valine \\
\hline Dimethyl sulfone & 30 & $0.122 \pm 0.066$ & $0.004 \pm 0.004^{*}$ & 0.022 & Sulfon e & Metab olis $m$ of the glucogenic am in o acid methionine \\
\hline 2-Aminoadipate & 1 & $0.012 \pm 0.020$ & $0.011 \pm 0.019$ & 0.822 & Alp ha am in o acid & $\begin{array}{l}\text { Lysine (ketogenic am in o acid) and saccharopin e } \\
\text { metabolism }\end{array}$ \\
\hline Saccharopine & 60 & $0.016 \pm 0.020$ & $0.013 \pm 0.020$ & 0.577 & $\begin{array}{l}\text { Glutam ic acid and } \\
\text { derivatives }\end{array}$ & Degradation pathway for the ketogenic am ino acid lysine \\
\hline Isoleucine & 43 & $0.061 \pm 0.051$ & $0.039 \pm 0.042^{*}$ & 0.049 & $\begin{array}{l}\begin{array}{l}\text { Isoleu cine and } \\
\text { derivatives }\end{array} \\
\end{array}$ & $\begin{array}{l}\text { Ketog en ic and glucogenic amino acid. Production and } \\
\text { form ation of hemoglobin and red blood cells }\end{array}$ \\
\hline Agmatine & 17 & $0.015 \pm 0.032$ & $0.038 \pm 0.143$ & 0.367 & Gu an idine & Metabolism of the glucogenic amino acid arginine \\
\hline Alanine & 18 & $0.181 \pm 0.070$ & $0.206 \pm 0.177$ & 0.435 & $\begin{array}{l}\begin{array}{l}\text { Alanine and } \\
\text { derivatives }\end{array} \\
\end{array}$ & $\begin{array}{l}\text { Glucose metabolism. Protein } s y n \text { thesis. Lym phocyte } \\
\text { reproduction, and immunity }\end{array}$ \\
\hline $\mathrm{N}, \mathrm{N}-\mathrm{D}$ imethylglycine & 51 & $0.014 \pm 0.020$ & $0.026 \pm 0.066$ & 0.283 & $\begin{array}{l}\text { Alp ha-am in o acids } \\
\text { and derivatives }\end{array}$ & Glycine, serine, methion in e, and betain e metab olis $m$ \\
\hline Histamine & 40 & $0.011 \pm 0.013$ & $0.014 \pm 0.024$ & 0.535 & 2-aryle th ylam in e & In flam $m$ ation and immunity \\
\hline Allantoin & 19 & $0.097 \pm 0.177$ & $0.027 \pm 0.052^{*}$ & 0.028 & Imidaz ole & Oxidative stress \\
\hline Ethanol & 32 & $0.071 \pm 0.102$ & $0.023 \pm 0.039^{*}$ & 0.012 & Prim ary alcohol & $\begin{array}{l}\text { Cellulose, hem icellulose, and lignin degradation in the } \\
\text { rumen }\end{array}$ \\
\hline
\end{tabular}

\section{Figure 5}

Baseline vs. Infected metabolite concentration (Mean \pm SD). Data were analyzed using Student's t-test with an $a<0.05$ delineating significant treatment effects (*), increase (dark purple), decrease (dark yellow). Values positively (light purple) or negatively correlated (light yellow) in the PCA during infection compared with the Baseline. Biochemical pathways: Grey = other; light blue = glycolysis/gluconeogenesis pathways, magenta $=$ triglycerides pathways, light green $=$ protein pathways. Prob $>F=p$-value for the whole model test, Italic $=$ parameter changed in both the ANOVA and the PCA. 


\begin{tabular}{|c|c|c|c|c|c|c|c|}
\hline${ }^{1}$ H-NMR Metabolite & ID & Baseline & $\begin{array}{l}\text { Infected with } \\
\text { BRSV }\end{array}$ & $\begin{array}{c}\text { Infected with } \\
\text { MH }\end{array}$ & Prob $>$ F & $\begin{array}{c}\text { Chemical } \\
\text { classification }\end{array}$ & Biochemical pathways \\
\hline Malonate & 47 & $1.755 \pm 0.576$ & $2.125 \pm 1.377$ & $1.921 \pm 0.272$ & 0.302 & $\begin{array}{l}\text { Dicarboxylic ac ids } \\
\text { and derivatives }\end{array}$ & Fa ty acid biosynthe sis \\
\hline 3-Hydroxy-3-m ethylglutarate & 7 & $0.012 \pm 0.018$ & $0.024 \pm 0.067$ & $0.015 \pm 0.02$ & 0.530 & $\begin{array}{l}\text { Dicarboxylic ac ids } \\
\text { and dervivatives }\end{array}$ & Ketone bod ies and leucine me tabolism \\
\hline Leucine & 46 & $0.124 \pm 0.216$ & $0.133 \pm 0.164$ & $0.084 \pm 0.042$ & 0.693 & $\begin{array}{l}\text { Leucine and } \\
\text { derivative s }\end{array}$ & Ketogenic amino acid. Protein synthesis \\
\hline 2-Aminoadipate & 1 & $0.012 \pm 0.020$ & $0.009 \pm 0.016$ & $0.014 \pm 0.021$ & 0.683 & Alpha amino acid & $\begin{array}{l}\text { Lysine (ketogenic amino ac id) and saccharopine } \\
\text { metabolis m }\end{array}$ \\
\hline Betaine & 21 & $0.196 \pm 0.649$ & $0.111 \pm 0.0119$ & $0.090=0.046$ & 0.695 & $\begin{array}{l}\text { Alpha-a mino acids } \\
\text { and dervatives }\end{array}$ & Choline me tabolism. Inflammation and immu nity \\
\hline Histamine & 40 & $0.011 \pm 0.013$ & $0.015 \pm 0.030$ & $0.013 \pm 0.015$ & 0.777 & 2-arylethylamine & Inflammation and immunity \\
\hline Ethanol & 32 & $0.071 \pm 0.102 \mathrm{~A}$ & $0.007 \pm 0.026 \mathrm{~B}$ & $0.043 \pm 0.044 \mathrm{~A}, \mathrm{~B}$ & 0.017 & Primary a kohol & $\begin{array}{l}\text { Cellulose, hemiceltulose, and lignin degradation in the } \\
\text { fumen }\end{array}$ \\
\hline Creatine & 25 & $0.257 \pm 0.291$ & $0.194 \pm 0.113$ & $0.146 \pm 0.055$ & 0.228 & $\begin{array}{l}\text { Alpha-a mino acids } \\
\text { and dervatives }\end{array}$ & Production of ATP for muscle contraction \\
\hline Creatine phosphate & 26 & $0.032 \pm 0.069$ & $0.047 \pm 0.123$ & $0.029=0.050$ & 0.784 & $\begin{array}{l}\text { Alpha-a mino acids } \\
\text { and derivatives }\end{array}$ & Production of ATP for muscle contraction \\
\hline Creatinine & 27 & $0.047 \pm 0.046$ & $0.036 \pm 0.027$ & $0.045 \pm 0.015$ & 0.530 & $\begin{array}{l}\text { Alpha-a mino acids } \\
\text { and derivatives }\end{array}$ & Production of ATP for muscle contraction \\
\hline Lactate & 45 & $0.521 \pm 0.316$ & $0.711 \pm 0.723$ & $0.699=0.511$ & 0.316 & $\begin{array}{l}\text { Alpha hydroxy acids } \\
\text { and derivatives }\end{array}$ & Glucose metabolis $m$ \\
\hline 3-Hydroxybutyrate & 8 & $0.094 \pm 0.090$ & $0.1710 \pm 0.290$ & $0.116 \pm 0.111$ & 0.295 & $\begin{array}{l}\text { Beta hydroxy acids } \\
\text { and derivatives }\end{array}$ & Ketone bod ies metabolis m. Fatty acid b ios ynthesis \\
\hline Acetate & 14 & $0.839 \pm 0.987$ & $0.723 \pm 1.071$ & $0.540 \pm 0.345$ & 0.573 & Carboxylic acid & $\begin{array}{l}\text { Gyc ogen and cholesterol synthesis. Fatty acids } \\
\text { de gradation }\end{array}$ \\
\hline Trim ethylamine N-oxide & 67 & $0.128=0.050$ & $0.150 \pm 0.124$ & $0.104 \pm 0.031$ & 0.214 & Trialkyl amine oxide & Choles terol metabolis m \\
\hline Carnitine & 23 & $0.015 \pm 0.016$ & $0.017 \pm 0.022$ & $0.018 \pm 0.025$ & 0.860 & Carnitine & Oxidation of branched-chain fatty acids \\
\hline Guanidoace tate & 39 & $0.097 \pm 0.066 \mathrm{~B}$ & $0.199 \pm 0.243 \mathrm{~A}$ & $0.101 \pm 0.072 \mathrm{~A}, \mathrm{~B}$ & 0.032 & $\begin{array}{l}\text { Alpha-amino acids } \\
\text { and derivatives }\end{array}$ & $\begin{array}{l}\text { Glucogen ic amin oacids (glycine, serine, arginine and } \\
\text { proline) me tabolism. Creatine phosphase pathway }\end{array}$ \\
\hline Agmatine & 17 & $0.015 \pm 0.032$ & $0.062 \pm 0.187$ & $0.005 \pm 0.013$ & 0.179 & Guanidine & Metabolis $m$ of the glu cogenic amino ac id arg inine \\
\hline Alanine & 18 & $0.181 \pm 0.070$ & $0.237 \pm 0.229$ & $0.165 \pm 0.041$ & 0.215 & $\begin{array}{l}\text { Alanine and } \\
\text { dervative s }\end{array}$ & $\begin{array}{l}\text { Glucose metabolis m. Protein synthe sis. Lymphocye } \\
\text { reproduction, and immunity }\end{array}$ \\
\hline Dimethyl sulfone & 30 & $0.122 \pm 0.066$ & $0.200 \pm 0.223$ & $0.185=0.031$ & 0.070 & Sulfone & Metabolis $m$ of the ghto cogenic amino ac id me thionine \\
\hline Formate & 33 & $0.155 \pm 0.130$ & $0.171 \pm 0.175$ & $0.140 \pm 0.016$ & 0.785 & Carboxylic acid & Glycine, se rine, and röbulose pa thways \\
\hline Glycine & 38 & $0.345 \pm 0.637$ & $0.199 \pm 0.154$ & $0.201 \pm 0.138$ & 0.433 & Alpha-a mino acid & Glucogen ic amin o acid. Protein synthesis \\
\hline $\mathrm{N}, \mathrm{N}$-Dimethylgycine & 51 & $0.014 \pm 0.02$ & $0.037 \pm 0.086$ & $0.012 \pm 0.007$ & 0.182 & $\begin{array}{l}\text { Alpha-a mino acids } \\
\text { and derivatives }\end{array}$ & Glycine, se rine, methionine, and betaine metabolism \\
\hline Cysteine & 28 & $0.009 \pm 0.023$ & $0.025 \pm 0.042$ & $0.017 \pm 0.026$ & 0.148 & \begin{tabular}{|l|}
$\begin{array}{l}\text { Cysteine and } \\
\text { derivative s }\end{array}$ \\
\end{tabular} & Glucogen ic amino acid. Protein synthesis \\
\hline 4-Aminobutyrate & 10 & $0.013=0.014$ & $0.014=0.015$ & $0.016 \pm 0.013$ & 0.855 & $\begin{array}{l}\text { Gamma a mino acids } \\
\text { and derivatives }\end{array}$ & GABA shunt. TCA cycle \\
\hline N-Methyllinydantoin & 55 & $0.050 \pm 0.068$ & $0.034 \pm 0.06$ & $0.047 \pm 0.051$ & 0.685 & Imidazoline & Creatinine degradation \\
\hline Arabinitol & 20 & $0.029 \pm 0.041$ & $0.003 \pm 0.014$ & $0.025 \pm 0.07$ & 0.113 & Sugar a k ohol & Pen tos e ph osphate pathway (PPP) \\
\hline Galactitol & 34 & $0.031 \pm 0.031$ & $0.025 \pm 0.026$ & $0.023 \pm 0.019$ & 0.559 & Sugar a k ohol & Galactose metabolis m \\
\hline Glucose & 35 & $5.141 \pm 7.097$ & $5.154 \pm 6.176$ & $3.529 \pm 0.628$ & 0.675 & Hexose & Primary s ource of energy for living organisms \\
\hline 2-Hydroxybutyrate & 3 & $0.003 \pm 0.005 \mathbf{B}$ & $0.004 \pm 0.008 \mathrm{~B}$ & $0.010=0.010 \mathrm{~A}$ & 0.006 & $\begin{array}{l}\text { Alpha hydroxy acids } \\
\text { and derivatives }\end{array}$ & Fa ty acid biosynthe sis. TCA cycle. ROS production \\
\hline Acetone & 16 & $0.005 \pm 0.003 \mathrm{~B}$ & $0.008=0.009 \mathrm{~A}, \mathbf{B}$ & $0.011=0.005 \mathrm{~A}$ & 0.008 & Ketone & Ketone Bodies Meta bolism \\
\hline Propionate & 58 & $0.011 \pm 0.011$ & $0.012 \pm 0.013$ & $0.007 \pm 0.01$ & 0.355 & Carboxylic acid & Faty acid biosynthe sis. Vitamin $\mathrm{K}$ me tabolism \\
\hline 2-Ox oghutarate & 6 & $0.007 \pm 0.022$ & $0.006 \pm 0.012$ & $0.011=0.018$ & 0.703 & $\begin{array}{l}\text { Gamma-ke to acids } \\
\text { and derivatives }\end{array}$ & $\begin{array}{l}\text { TCA cycle. Metabolism of the glucogenic amino ac id s } \\
\text { alanine, a spartate, and g tutamate. Ammon ia recycling }\end{array}$ \\
\hline Isobutyrate & 42 & $0.009 \pm 0.008 \mathrm{~A}$ & $0.006 \pm 0.007 \mathrm{~A}, \mathrm{~B}$ & $0.002 \pm 0.005 \mathrm{~B}$ & 0.009 & Carboxylic a cid & Branched fatty acid \\
\hline 3-Hydroxyisobutyrate & 9 & $0.002 \pm 0.007 \mathrm{~B}$ & $0.007 \pm 0.013 \mathrm{~A}, \mathbf{B}$ & $0.010=0.012 \mathrm{~A}$ & 0.039 & $\begin{array}{l}\text { Beta hydroxy acids } \\
\text { and derivatives }\end{array}$ & Metabolis $m$ of the ghocogenic amino ac id valine \\
\hline$\pi$-Methylhistidine & 72 & $0.025 \pm 0.018 \mathbf{A}, \mathbf{B}$ & $0.019 \pm 0.017 \mathrm{~B}$ & $0.036 \pm 0.02 \mathrm{~A}$ & 0.027 & $\begin{array}{l}\text { Histidine and } \\
\text { derivative s }\end{array}$ & $\begin{array}{l}\text { Syn thes is and degradation of the glucogenic amino } \\
\text { ac id histidine }\end{array}$ \\
\hline 5-Aminolevulinate & 12 & $0.020 \pm 0.062$ & $0.013 \pm 0.015$ & $0.016 \pm 0.012$ & 0.847 & $\begin{array}{l}\text { Dela amino acids and } \\
\text { derivative } s\end{array}$ & Porphyrin, glycine, and serine metabolis $\mathrm{m}$ \\
\hline Isoleucine & 43 & $0.061 \pm 0.051$ & $0.045 \pm 0.042$ & $0.031 \pm 0.042$ & 0.096 & $\begin{array}{l}\text { Isoleucine and } \\
\text { derivative } 3\end{array}$ & $\begin{array}{l}\text { Ketogenic and glvcogen ic amin o acid. Production and } \\
\text { formation of hemoglobin and red blood cells }\end{array}$ \\
\hline Saccharopine & 60 & $0.016 \pm 0.020$ & $0.013 \pm 0.020$ & $0.014 \pm 0.021$ & 0.837 & $\begin{array}{l}\text { Glutamic acid and } \\
\text { derivative s }\end{array}$ & $\begin{array}{l}\text { Degradation path ray for the ketogenic amino ac id } \\
\text { lysine }\end{array}$ \\
\hline 2-Hydroxyisobutyrate & 4 & $0.002 \pm 0.001$ & $0.001 \pm 0.001$ & $0.002 \pm 0.001$ & 0.176 & $\begin{array}{l}\text { Alpha hydroxy acids } \\
\text { and derivatives }\end{array}$ & $\begin{array}{l}\text { Catabolism of threonine and me thionine. Gluta thione } \\
\text { an abolism (cyse ine formation patway) }\end{array}$ \\
\hline N-Acetylglycine & 53 & $0.002 \pm 0.003$ & $0.002 \pm 0.006$ & $0.003 \pm 0.004$ & 0.597 & $\begin{array}{l}\text { N-acyl-alpha amino } \\
\text { acid }\end{array}$ & Metabolis $m$ of the ghe cogenic amino ac id glycine \\
\hline Valine & 70 & $0.041 \pm 0.059$ & $0.063 \pm 0.066$ & $0.036 \pm 0.049$ & 0.346 & Valine and de rivatives & $\begin{array}{l}\text { Glucogen is amin oacid. Valine, leuc ine, and is ole ucine } \\
\text { degrada tion. Propanoase metabolis } m \text {. }\end{array}$ \\
\hline
\end{tabular}

\section{Figure 6}

Metabolite concentration (Mean $\pm S D$ ) for dairy calves challenged with BRSV and M. haemolytica (MH). Categories not connected by the same letter between Baseline, BRSV, and MH were significantly different $(p<0.05)$; increase (dark purple), decrease (dark yellow). Values positively (light purple) or negatively correlated (light yellow) in the PCA during infection compared with the Baseline. Biochemical pathways: Grey = other; light blue = glycolysis/gluconeogenesis pathways, magenta = triglycerides pathways, light 
green $=$ protein pathways. Prob $>\mathrm{F}=\mathrm{p}$-value for the whole model test, Italic $=$ parameter changed in the ANOVA and the PCA.
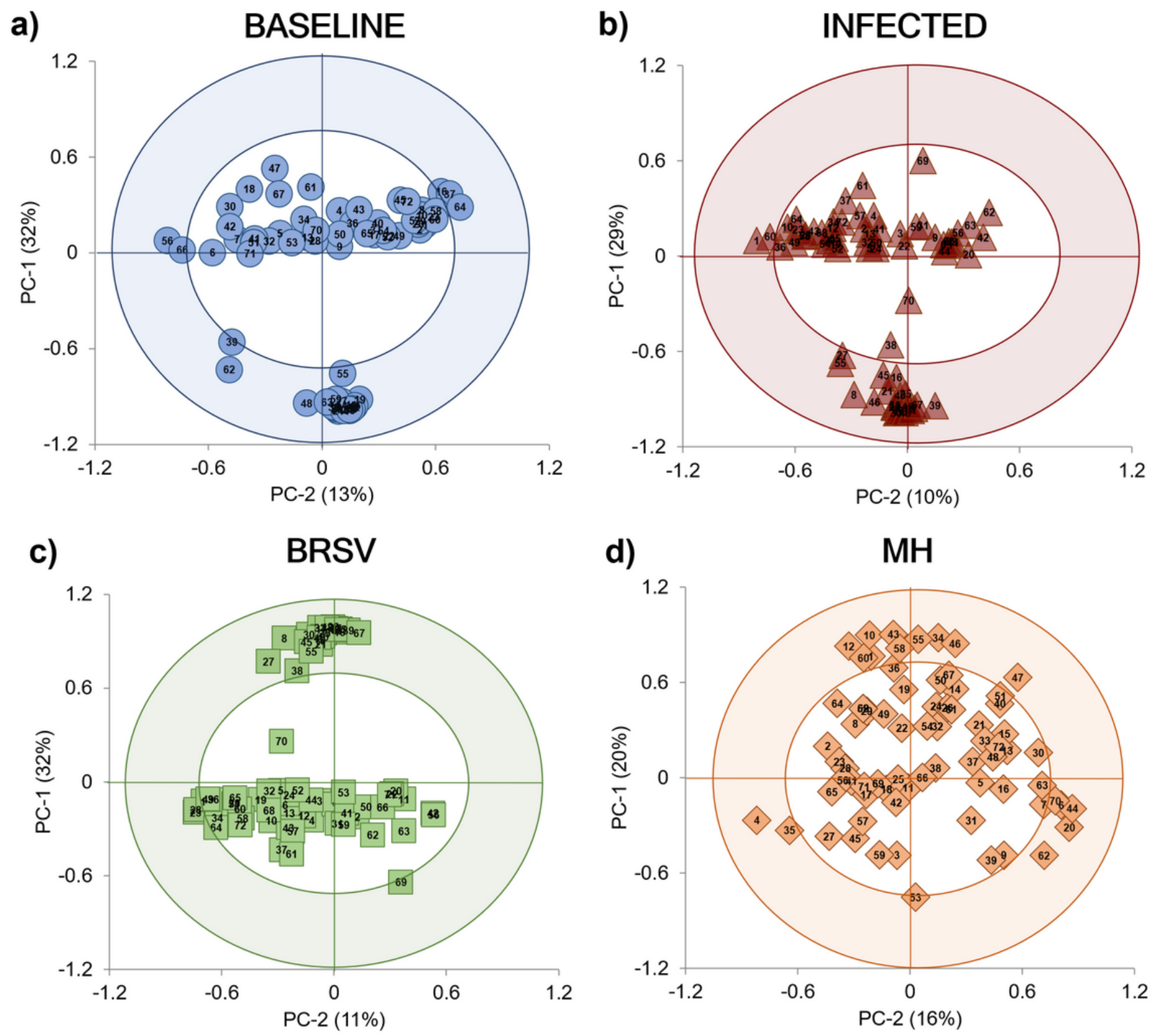

\section{Figure 7}

Principal component analysis (PCA) correlation loadings plots for the concentration ( $\mathrm{mM}$ ) of the selected $1 \mathrm{H}$-NMR metabolites $(\mathrm{n}=72)$. The variables inside the outer circle (colored area) have the greatest influence on database variability and are positive or negative correlated during the Baseline or Infected stages; the points inside the inner circle are thought to have low or no influence. (a) Baseline $(n=35)$; two PCs explained $45 \%$ of the variance. (b) Infected data points from both challenge studies $(n=35)$, two PCs explained $39 \%$ of the variation of the database. (c) Infected calves with BRSV $(n=20)$, two PCs explained $43 \%$ of the variation of the database. (d) Infected or challenged calves with M. haemolytica $(M H)(n=15)$, 
two PCs explained $36 \%$ of the database variation. Each plasma sample, on average, contained $43 \pm 8$ of the selected metabolites.
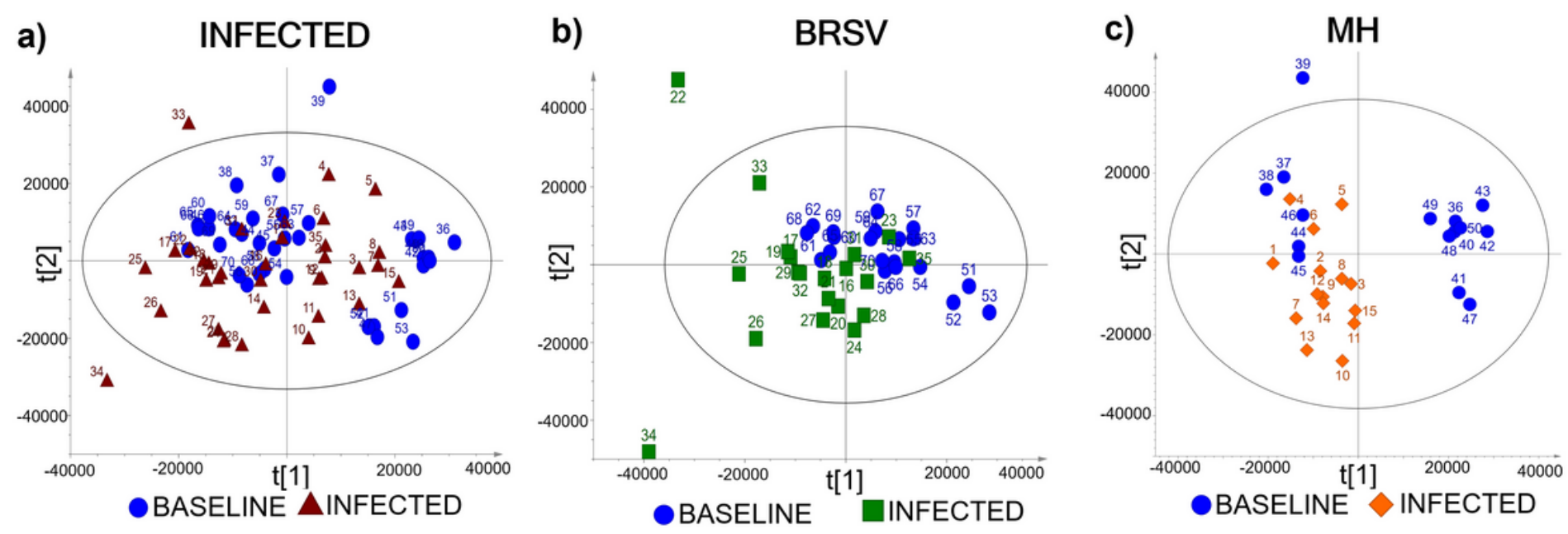

Figure 8

Principal component analysis (PCA) scores plots for $1 \mathrm{H}-\mathrm{NMR}$ spectra from Baseline and Infected blood plasma samples. (a) PCA scores plot $(n=70)$ from the general infection database $(P C-2: R 2 X=0.34, Q 2=$ 0.26). (b) PCA scores plot $(n=40)$ from the BRSV challenge (PC-2: $R 2 X=0.34, Q 2=0.10)$. (c) PCA scores plot $(n=30)$ from the M. haemolytica $(M H)$ challenge $(P C-2: R 2 X=0.45, Q 2=0.25)$. Labels above the scores indicate the sample ID (Table S1). 
a)

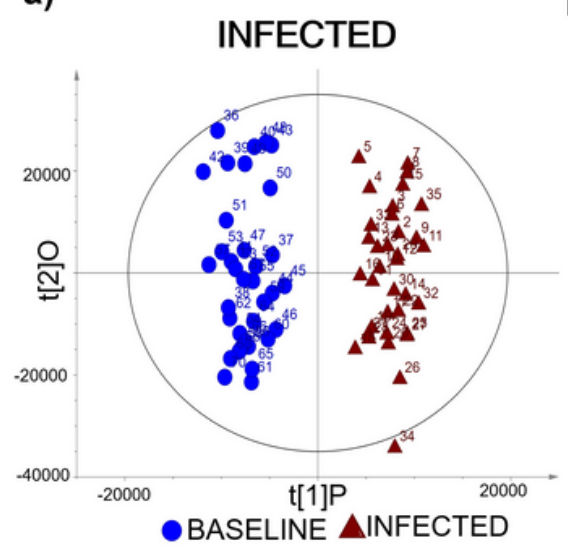

b)
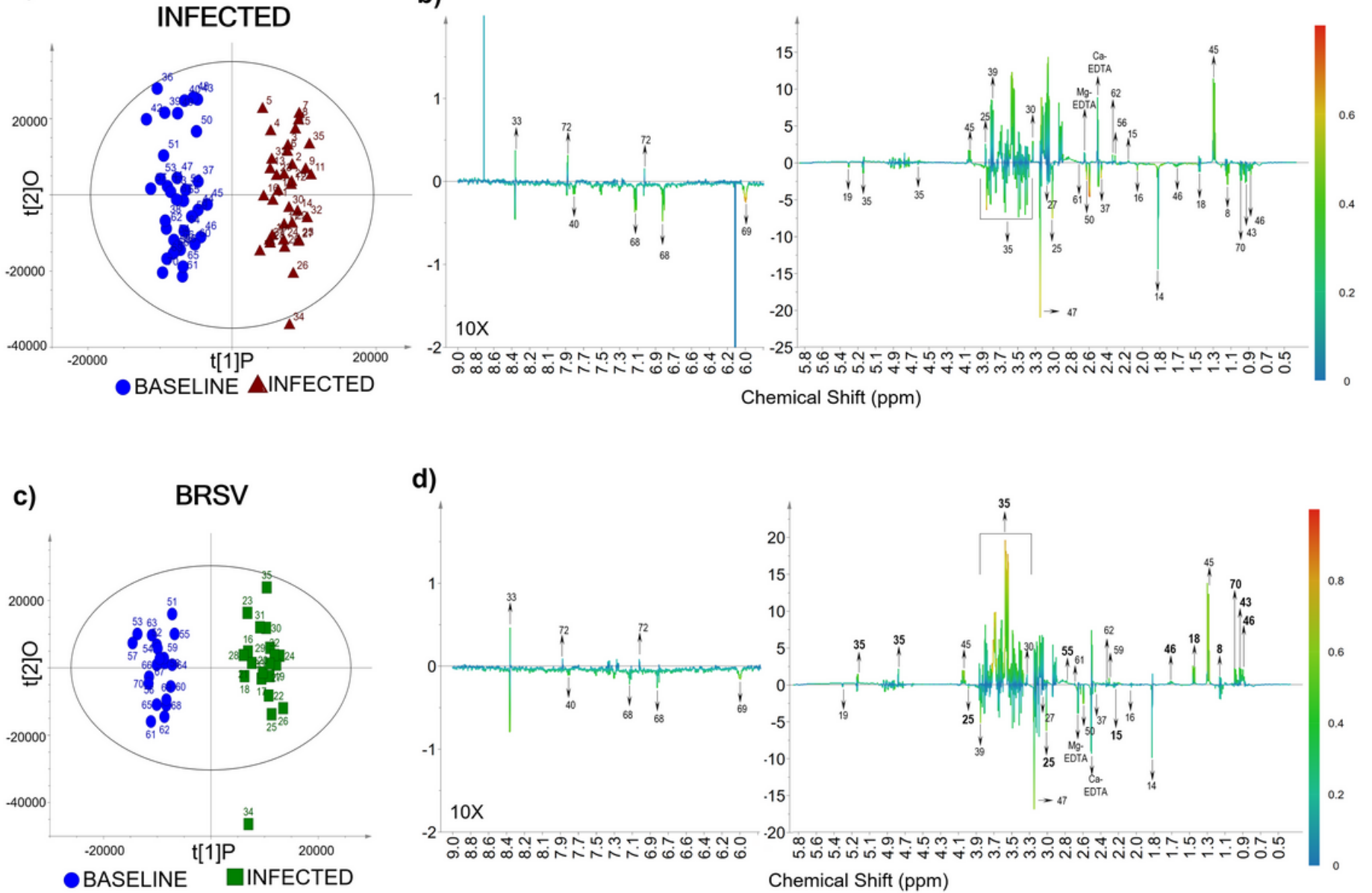

d)

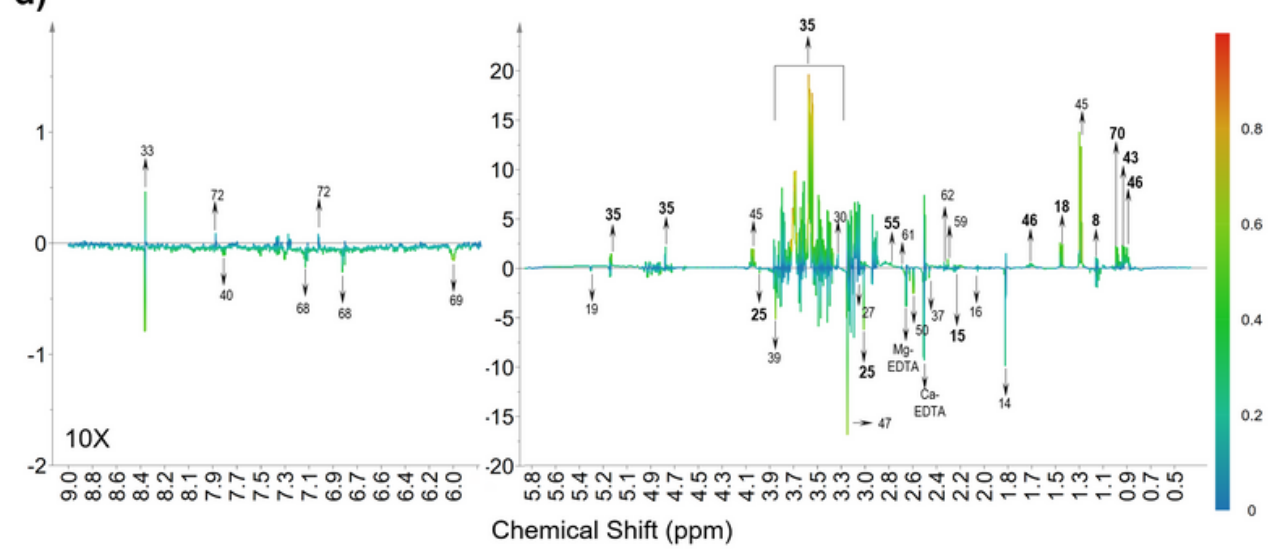

e)

$\mathrm{MH}$

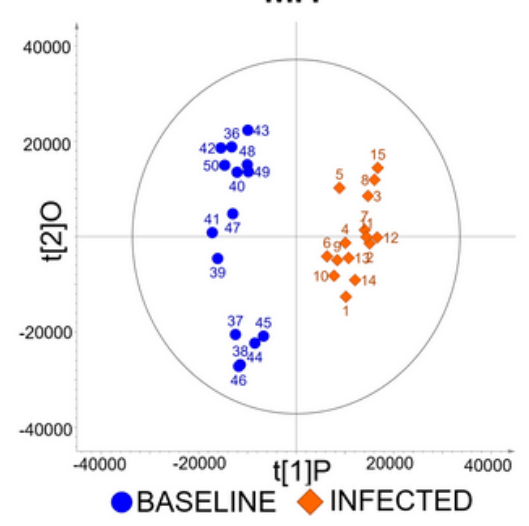

f)

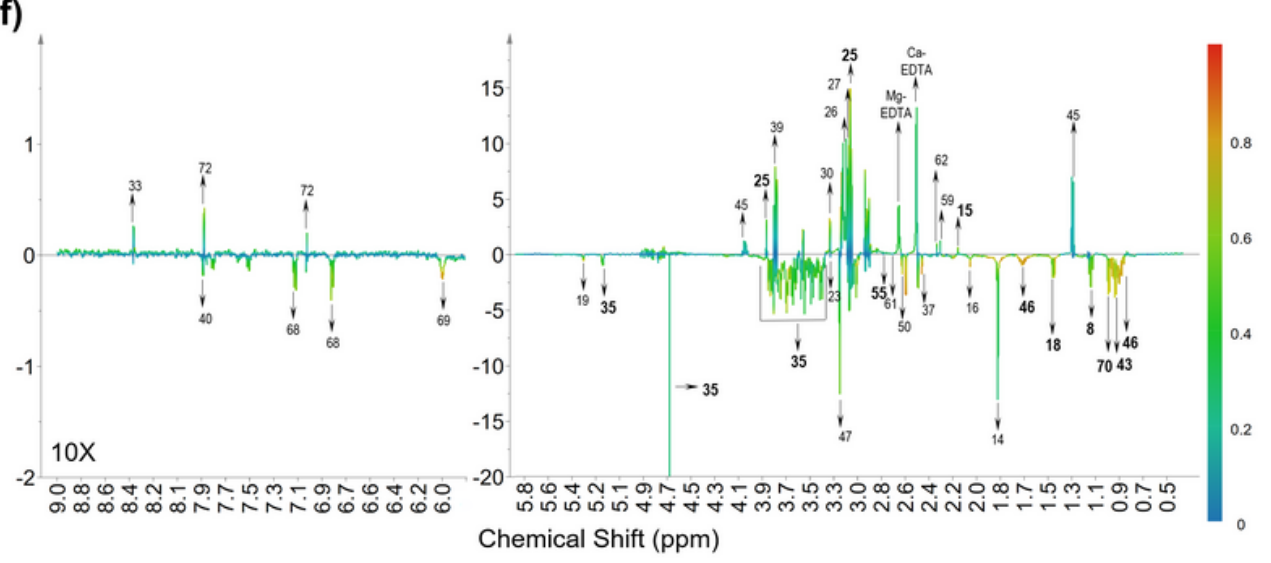

Figure 9

OPLS - DA scores plots resulting from $1 \mathrm{H}-\mathrm{NMR}$ spectra of blood plasma as well as the corresponding coefficient loading plots. The color map depicts the significance of spectral signals between the two categories (Baseline and Infected). (a) OPLS-DA scores plot from the general infection database $(n=70)$. (b) Coefficient loadings plot for general infection. (c) OPLS-DA scores plot from the BRSV challenge $(\mathrm{n}=$ 40). (d) Coefficient loadings plot from the BRSV challenge. (e) OPLS-DA scores plot from the M. haemolytica $(\mathrm{MH})$ challenge $(n=30)$. (f) Coefficient loadings plot from the M. haemolytica challenge. 
Labels above the scores indicate the sample's ID, and above the peaks show the metabolite's ID. To improve the visualization of the peaks in the coefficient loadings plots, the size of the region between 6.0$9.0 \mathrm{ppm}$ was increased 10X.

\section{Supplementary Files}

This is a list of supplementary files associated with this preprint. Click to download.

- NMRBRDSupplementaryMaterial.pdf 